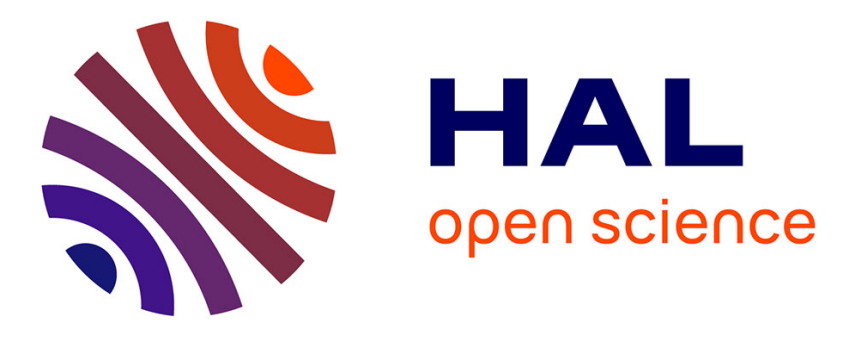

\title{
Developmental improvements in voluntary control of behavior: Effect of preparation in the fronto-parietal network?
}

\author{
Nadia Alahyane, Donald C Brien, Brian C Coe, Patrick W Stroman, Douglas \\ P Munoz
}

\section{To cite this version:}

Nadia Alahyane, Donald C Brien, Brian C Coe, Patrick W Stroman, Douglas P Munoz. Developmental improvements in voluntary control of behavior: Effect of preparation in the fronto-parietal network? NeuroImage, 2014, 98, pp.103-117. 10.1016/j.neuroimage.2014.03.008 . hal-03131286

\author{
HAL Id: hal-03131286 \\ https://hal.science/hal-03131286
}

Submitted on 4 Feb 2021

HAL is a multi-disciplinary open access archive for the deposit and dissemination of scientific research documents, whether they are published or not. The documents may come from teaching and research institutions in France or abroad, or from public or private research centers.
L'archive ouverte pluridisciplinaire HAL, est destinée au dépôt et à la diffusion de documents scientifiques de niveau recherche, publiés ou non, émanant des établissements d'enseignement et de recherche français ou étrangers, des laboratoires publics ou privés. 


\title{
Developmental improvements in voluntary control of behavior: Effect of preparation in the fronto-parietal network?
}

\author{
Nadia Alahyane **, Donald C. Brien, Brian C. Coe, Patrick W. Stroman, Douglas P. Munoz * \\ Centre for Neuroscience Studies, Queen's University, Kingston, Ontario K7L 3N6, Canada
}

\section{A R T I C L E I N F O}

\section{Article history:}

Accepted 9 March 2014

Available online 15 March 2014

\section{Keywords:}

Saccade

Cognitive control

Task set

fMRI

Child development

Frontal cortex

\begin{abstract}
A B S T R A C T
The ability to prepare for an action improves the speed and accuracy of its performance. While many studies indicate that behavior performance continues to improve throughout childhood and adolescence, it remains unclear whether or how preparatory processes change with development. Here, we used a rapid event-related fMRI design in three age groups (8-12,13-17, 18-25 years) who were instructed to execute either a prosaccade (look toward peripheral target) or an antisaccade (look away from target) task. We compared brain activity within the core fronto-parietal network involved in saccade control at two epochs of saccade generation: saccade preparation related to task instruction versus saccade execution related to target appearance. The inclusion of catch trials containing only task instruction and no target or saccade response allowed us to isolate saccade preparation from saccade execution. Five regions of interest were selected: the frontal, supplementary, parietal eye fields which are consistently recruited during saccade generation, and two regions involved in top down executive control: the dorsolateral prefrontal and anterior cingulate cortices. Our results showed strong evidence that developmental improvements in saccade performance were related to better saccade preparation rather than saccade execution. These developmental differences were mostly attributable to children who showed reduced fronto-parietal activity during prosaccade and antisaccade preparation, along with longer saccade reaction times and more incorrect responses, compared to adolescents and adults. The dorsolateral prefrontal cortex was engaged similarly across age groups, suggesting a general role in maintaining task instructions through the whole experiment. Overall, these findings suggest that developmental improvements in behavioral control are supported by improvements in effectively presetting goal-appropriate brain systems.
\end{abstract}

(c) 2014 Elsevier Inc. All rights reserved.

\section{Introduction}

The ability to select and generate appropriate behaviors, according to goals or changes in the environment, undergoes important developmental changes between infancy and adulthood (Durston and Casey, 2006; Johnson, 2001; Luna et al., 2010). This cognitive control of behavior can be examined with the antisaccade task where participants are instructed to resist looking toward a flashed visual target and instead, to execute a saccade to the opposite side (Hallett, 1978; Munoz and Everling, 2004). The antisaccade task is often compared to a basic oculomotor task, the prosaccade task, where participants are required to simply look at the target when appearing on the screen. Many behavioral studies revealed that both prosaccade and antisaccade reaction times,

\footnotetext{
* Correspondence to: D.P. Munoz, Centre for Neuroscience Studies, Queen's University, Botterell Hall, Room 234, 18 Stuart St., Kingston, Ontario K7L 3N6, Canada. Fax: + 1613 5336840 .

** Correspondence to: N. Alahyane, Laboratoire Vision Action Cognition, Université Paris Descartes Centre Henri Piéron - UFR Institut de Psychologie 71, avenue Edouard Vaillant 92774 Boulogne-Billancourt Cedex.

E-mail addresses: alahyanen@gmail.com (N. Alahyane),doug.munoz@queensu.ca (D.P. Munoz)
}

and errors in the antisaccade task (i.e., unwanted prosaccades made toward the target) which probe response inhibition, gradually decrease through development to stabilize around late adolescence or young adulthood (Fischer et al., 1997; Klein and Foerster, 2001; Kramer et al., 2005; Luna et al., 2004; Munoz et al., 1998; Ordaz et al., 2010; for review, Luna et al., 2008). Yet, it is only recently that a handful of studies combining functional magnetic resonance imaging (fMRI) and eye movement recording have emerged to examine the neural correlates underlying the developmental improvements in antisaccade control (Hwang et al., 2010; Velanova et al., 2008, 2009).

In the present study, we asked the question: which specific process that composes saccade generation changes over development (8-25 years) and contributes to age-related changes in saccade performance? Indeed, in most saccade experiments, an instruction is present at the start of the trial (conveyed for example by the color or shape of a central cue) that signals which task to perform (prosaccade or antisaccade). Then, a peripheral target appears, prompting the participants to execute the correct response (look toward target location, or away, respectively). Therefore, a saccade trial can be decomposed into an instruction-related epoch and a target-related epoch. The instruction-related epoch is crucial because it allows participants to 
get ready, decide and prepare for the appropriate action in advance of target appearance (Connolly et al., 2002). Importantly, this ability to prepare for upcoming actions optimizes performance (Chikazoe et al., 2009; Meiran and Daichman, 2005; Monsell, 2003): responses are initiated faster and inappropriate responses are more efficiently inhibited. We hypothesize that improvements in saccade initiation and inhibition from childhood to adulthood (Luna et al., 2008) may be related to agerelated enhancements in response preparation. A clue in favor of our hypothesis can be found in a behavioral study which showed that participants 8-31 years-old responded faster and more accurately in the antisaccade task when given more time to prepare during the instruction period (Ordaz et al., 2010). This suggests that the basic preparatory processes, which are engaged during instruction to establish the antisaccade task set, are in place in children. However, because the beneficial effects on performance were similar across ages, and performance in children never reached adult levels, the authors suggested that 'developmental improvements in rates of inhibitory successes and latencies to inhibit a response are not supported by limitations in the time needed to prepare a response. Rather, persistent age-related differences in inhibitory control may instead reflect qualitative differences in control aspects of preparatory processing'. Unfortunately, prosaccade trials were not tested to verify whether possible improvements in preparation were related to both saccade types, given that prosaccade performance also changes with development (Luna et al., 2008).

FMRI studies in adults have revealed that preparation of antisaccades and prosaccades involves a core fronto-parietal cortical network, including the frontal eye field (FEF), supplementary eye field (SEF), parietal eye field (PEF), dorsolateral prefrontal cortex (DLPFC), and anterior cingulate cortex (ACC) (Brown et al., 2007; Connolly et al., 2002, 2005; Curtis and Connolly, 2008; Curtis and D'Esposito, 2003; DeSouza et al., 2003; Ford et al., 2005), consistent with neurophysiological studies in monkey (Amador et al., 2004; Everling and Munoz, 2000; Johnston and Everling, 2006; Johnston et al., 2007). The FEF is an important node in the saccade network, carrying set-related signals for antisaccades and prosaccades to the superior colliculus and premotor circuitry (Bruce and Goldberg, 1985; Munoz and Everling, 2004; Schiller et al., 1980). Importantly, in both humans and monkeys, levels of preparatory activity in the FEF predict successful performance in the antisaccade task (Curtis and D'Esposito, 2003; Everling and Munoz, 2000; but see Ford et al., 2005), and how fast a correct prosaccade or antisaccade will be initiated (Connolly et al., 2005; Everling and Munoz, 2000). These same frontal and parietal regions are recruited in adults during saccade execution after target appearance (Brown et al., 2007; Curtis and Connolly, 2008; Curtis and D'Esposito, 2003; DeSouza et al., 2003; Ford et al., 2005). However, contrary to the FEF, SEF and PEF, significant differences in ACC and DLPFC activity between antisaccades and prosaccades were observed only during preparation (Brown et al., 2007). It was suggested that these two areas provide top down executive control by biasing the oculomotor circuitry for antisaccade performance before target appearance (Brown et al., 2007; Johnston et al., 2007). Finally, this fronto-parietal network is also recruited by children ( $>8$ years-old) and adolescents when making correct antisaccades, although with different magnitudes compared to adults (Luna et al., 2001; Velanova et al., 2008, 2009). However, these previous studies did not dissociate activation related to antisaccade preparation and activation related to execution.

Here, we used fMRI in participants from 8 to 25 years old while they performed interleaved prosaccade and antisaccade tasks. Our approach is hypothesis-driven and focused on the core fronto-parietal network involved in saccade control and engaged in children, adolescents and adults. We tracked developmental changes in brain activity in the FEF, SEF, PEF, DLPFC and ACC during two separate epochs: 1) during instruction to make a prosaccade or antisaccade while subjects were preparing for the task and 2) after target appearance when they executed the correct saccade. To temporally dissociate saccade preparation and saccade execution, some fMRI studies used long instruction periods (Connolly et al., 2002; Curtis and Connolly, 2008; Curtis and D'Esposito, 2003; DeSouza et al., 2003; Ford et al., 2005), which are necessary to avoid an overlap of the hemodynamic responses related to task instruction and target appearance. Although adults can maintain preparation for 6 to $14 \mathrm{~s}$, this is not suitable for young participants (Okazaki et al., 2004; Olivier and Rival, 2002). Additionally, maintaining preparation for so long may require extra processes (e.g., prolonged memorization of instructions, 'waiting' strategies). To circumvent these disadvantages while being able to isolate saccade preparation from saccade execution, we chose another approach which consisted of intermixing catch trials containing the instructional cue to make a prosaccade or antisaccade, but no target presentation or saccade response (Brown et al., 2007; Geier et al., 2010). If, as we hypothesize, developmental improvements in saccade performance are related to more efficient preparatory processes, we predicted that brain activity in the fronto-parietal network should correlate with development primarily during task instruction. These developmental effects on preparatory activity should be found for both prosaccade and antisaccade tasks because behavioral performance improves with age in both tasks. Overall this would suggest that immaturities in behavioral control may be related to immaturities in effectively presetting goal-appropriate response pathways.

\section{Materials and methods}

Subject recruitment and experimental procedures were reviewed and approved by the Health Sciences Human Research Ethics Board at Queen's University, and followed the principles of the Declaration of Helsinki.

\section{Participant recruitment and selection}

Originally, 161 subjects ranging from 8 to 25 years old ( 26 between 18 and 25 years-old) were recruited from the greater area of Kingston through advertisements in local newspapers and flyers around Queen's university campus. They were screened for history of psychiatric or neurological condition, education, medication and substance use, based on a custom-made questionnaire. The volunteers aged below 18 years came for an initial visit (30-45 min) to tour the MRI facility and familiarize themselves with the MRI settings, safety procedures, and eye movement tasks. Once they were comfortable with the task demands, they were trained to remain still in a mock $0 \mathrm{~T}$ scanner while performing one or two runs of the saccade tasks (5-10 min). Eye movements were not recorded and no feedback about their performance was given. After this session, 31 families declined to participate in the subsequent fMRI session. Three were unable to remain still in the mock scanner and six had a learning disability or neurodevelopmental disorder. Three other families did not come at the given appointment. In total, 92 young participants 8-17 yearsold were enrolled in the fMRI study (90-120 min). The 26 adult volunteers, who reported no brain disorder or psychoactive medication, did not receive the training session (but were invited to do so if interested) and participated in the fMRI session only. Adult participants and parents or guardians of minors signed informed written consent after the procedures were reviewed with the experimenter. Children also gave written assent to confirm that they understood the procedures and were willing to participate. All volunteers were given 5 min of practice of the saccade tasks prior to entering the MRI room. Vision was normal or corrected-to-normal by wearing contact lenses. Volunteers received $\$ 20$ per hour compensation for their participation.

After the fMRI session, data from 24 participants were immediately excluded from subsequent analyses because of technical failure with the MRI or eye tracking equipment ( $\mathrm{n}=8$; 9 -15 years; 6 males), dental braces or a retainer causing artifacts in the functional images ( $\mathrm{n}=4$; 9-13 years; 1 male), falling asleep in the scanner 
( 3 children: 9-11 years; 1 male; 3 adults: 20-23 years; 1 male), noncompliance with the task $(\mathrm{n}=4 ; 9-12$ years; 1 male), and withdrawal by the volunteer after one functional run ( $\mathrm{n}=2$ males; 9,14 years). Data from 15 additional participants (8-17 years) were excluded because they did not meet the quality assurance criteria for image artifacts and motion (see Preprocessing section). In sum, data from 31 children, 25 adolescents and 23 adults are reported here (see Table 1). All 79 participants were right-handed except two children who were left-handed. Finally, despite the relatively high attrition rate and practice in young participants compared to adults, it is important to note that we found similar saccade performance and similar developmental trends (see Results section for details) to previous behavioral studies (e.g., Luna et al., 2004; Munoz et al., 1998).

\section{Behavioral paradigm}

Participants were scanned while performing between 6 and 8 runs of saccade tasks depending on their motivation or tiredness in a rapid fMRI event-related design (Fig. 1), with rest breaks in between ( 1 child performed 4 runs only, 1 child and 1 adult performed 5 runs). The mean number of collected runs was similar across children $(6.6+/-1.1)$, adolescents $(6.9+/-1.01)$ and adults $(6.9+/-1.1$; one-way ANOVA: $\left.F_{2,76}<1\right)$. The visual stimuli and duration of each run ( $4 \mathrm{~min}, 37.5 \mathrm{~s}$ ) were chosen to make the experiment more entertaining and enjoyable for the young participants and keep them engaged during the entire run.

Each run comprised 64 trials: 16 prosaccade trials, 16 antisaccade trials, 8 procatch trials, 8 anticatch trials, and 16 fixation trials. Each saccade trial (Fig. 1A) started with $1 \mathrm{~s}$ of fixation of a central coin on a black screen. The coin then turned into a red crab or green turtle for $1.3 \mathrm{~s}$, followed by a 200 -ms gap with no stimulus. A gap was inserted because it is known to release active fixation and facilitate preparation of the upcoming saccade before target presentation, which leads to reduced saccade reaction times and higher propensity to make unwanted prosaccades in the antisaccade task (Dorris and Munoz, 1995; Everling et al., 1998; Munoz and Corneil, 1995). After the gap, a peripheral coin was flashed for $100 \mathrm{~ms}$ to the right or the left, at eccentricity of either $6^{\circ}$ or $7^{\circ}$, with equal probability. Then the screen was blank for $1.4 \mathrm{~s}$. During this period, participants were required to execute a prosaccade or an antisaccade according to the instructional cue and then hold their gaze at that eccentric location until a visual coin came back to the center for $500 \mathrm{~ms}$ indicating the start of the next trial. When the central cue was a green turtle (prosaccade task), participants were asked to direct their eyes to the peripheral coin when appearing on the screen. When the cue was a red crab (antisaccade task), they were asked to refrain from looking at the coin and instead, to direct their eyes away from it, to the opposite position. Participants were asked to respond as quickly and accurately as possible. They were encouraged to do the best they could and to correct their mistakes if they "thought" they made any (for example, they made a prosaccade instead of an antisaccade, and conversely). No feedback regarding their performance was given. They were also instructed that in some trials, the central cue (green turtle or red crab) was not followed by a peripheral coin (Fig. 1B). Instead, the instruction cue was followed by a black screen for $1700 \mathrm{~ms}$ during which participants were asked to maintain fixation at center until the appearance of the central coin indicating the end of the trial. These

Table 1

Participant characteristics.

\begin{tabular}{llll}
\hline & $8-12$ years & $13-17$ years & $18-25$ years \\
\hline $\mathrm{n}$ & 31 & 25 & 23 \\
Mean age (SD) & $10.4(1.3)$ & $14.9(1.3)$ & $21.7(1.8)$ \\
Males & 14 & 15 & 10 \\
\hline
\end{tabular}

SD: standard deviation.

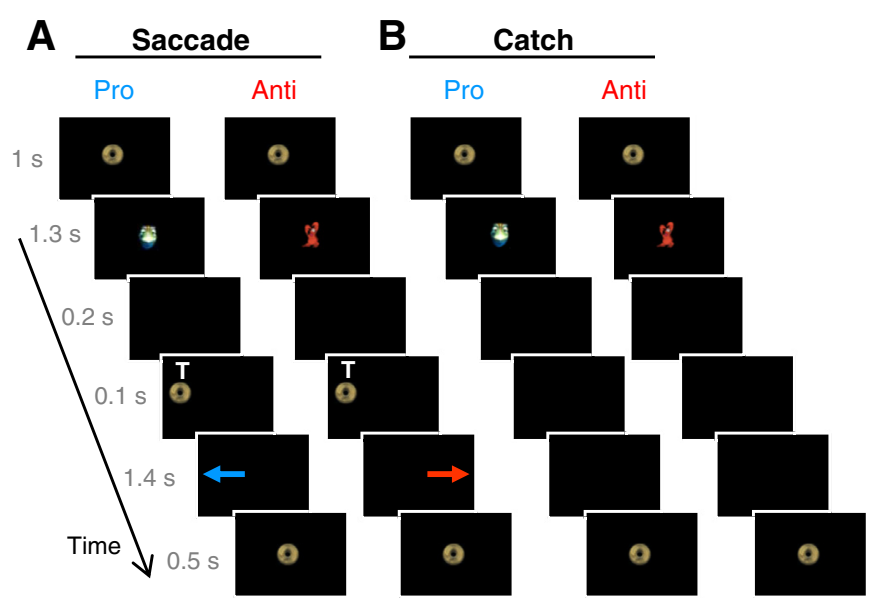

Fig. 1. Behavior paradigm. Participants had to execute two tasks: to look toward peripheral target $\mathrm{T}$ position (pro-saccade, blue arrow) upon its appearance, or to prevent from looking at $\mathrm{T}$ and instead to direct their eyes to the opposite side (anti-saccade, red arrow). A. In saccade trials, a central cue, presented $1.5 \mathrm{~s}$ in advance of T onset, instructed the subjects which task was to be performed. A green turtle indicated to execute a prosaccade, and a red crab indicated to make an antisaccade. B. In catch trials, only the instructional cue was presented. The different types of trials were randomly interleaved.

catch trials provided an important measure of task preparation, isolated from task execution related to target presentation (Brass and von Cramon, 2002; Brown et al., 2007; Curtis et al., 2005; Geier et al., 2010; Ollinger et al., 2001a,b; Orr and Weissman, 2009). Indeed, because all trials were randomly interleaved and the participants did not know during the presentation of the instructional cue whether it would be followed by a target or not, they had to prepare for the appropriate saccade task ('look toward' or 'look away') until the peripheral target was presented, or not. A ratio of 2:1 between saccade trials ( $\mathrm{n}=16$ per instruction type) and catch trials ( $\mathrm{n}=8$ per instruction type) was chosen to favor the tendency to respond and therefore, to increase the need to actively prepare for the upcoming saccade task. Finally, 16 neutral fixation trials were included (not illustrated) containing a central fixation coin for three different durations: $1.5 \mathrm{~s}(\mathrm{n}=8), 3 \mathrm{~s}(\mathrm{n}=4)$, and $4.5 \mathrm{~s}(\mathrm{n}=4)$. The variable length introduced temporal jitter necessary in rapid event-related designs to optimize the separation of the overlapping estimated blood oxygenation level-dependent (BOLD) responses elicited by the different trial types (Burock et al., 1998; Dale, 1999; Ollinger et al., 2001a,b). Moreover these neutral trials served as a baseline condition in the fMRI analysis, in addition to a $16.5 \mathrm{~s}$ long neutral fixation period that ended each run. This latter fixation period also allowed for the hemodynamic response to return toward baseline. The order of trials, type of instruction and target location were randomly intermixed within each run.

\section{Image acquisition}

Imaging data were collected from a $3 \mathrm{~T}$ whole-body Siemens Magnetom Trio system with a receiver head coil. Padding was placed around the head to minimize head motion. At the start of the session, a high-resolution anatomical MP-RAGE 3D T $\mathrm{T}_{1}$-weighted scan was acquired (repetition time TR $=1760 \mathrm{~ms}$, echo time $\mathrm{TE}=2.2 \mathrm{~ms}$, flip angle $\mathrm{FA}=9^{\circ}, 1 \mathrm{~mm}$ isovoxel resolution, 176 slices). During this scan, young participants watched a cartoon whereas adults had the choice to listen to music if they wanted. The purpose of cartoons was to help children to relax from the beginning while getting used to the scanner environment, and to enhance their motivation. Audio was provided through high-quality stereo headphones (NordicNeuroLab NNL) which were also used to attenuate the scanner noise ( $35 \mathrm{~dB}$ sound protection). Functional $\mathrm{T}_{2}{ }^{*}$-weighted echo-planar images (EPIs) sensitive 
to blood oxygen level dependent (BOLD) contrast were then acquired interleaved $\left(\mathrm{TR}=1500 \mathrm{~ms}, \mathrm{TE}=30 \mathrm{~ms}, \mathrm{FA}=72^{\circ}\right.$, field-of-view $=$ $211 \times 211 \mathrm{~mm}$, matrix size $=64 \times 64,3.3 \mathrm{~mm}$ isovoxel resolution, 24 axial slices from the top of the brain). Six to eight functional runs were collected per participant (see beginning of Behavioral paradigm section), each with 185 volumes. For each run, the first two volumes (containing a central fixation coin) allowed for signal equilibration and were subsequently discarded.

\section{Eye tracking}

Along with functional imaging, eye position was monitored at $120 \mathrm{~Hz}$ with an ISCAN video based eye tracking system (ISCAN Inc., Burlington, MA, USA) equipped with an infrared fiber-optic lightsource that was attached to the head coil and directed to the right eye. Task performance was also watched online to verify that participants were performing the experiment while in the scanner bore. A nine-point calibration of eye position was performed before the first run and repeated between runs when necessary. The visual display and behavioral experimental design were controlled by a PC computer running E-prime (Psychology Software Tools, Pittsburgh, PA, USA). Visual images were back-projected via a NEC LT265 DLP projector (Tokyo, Japan) with a refresh rate of $60 \mathrm{~Hz}$ on a highcontrast screen (DA-LITE) at the head of the bore and viewed by the participant through a mirror mounted on the head coil.

\section{Behavioral data analysis}

Trials were scored offline by custom-made MatLab (version 7.9, MathWorks Inc.) programs and subsequent statistical analyses were performed with Statistica (version 9.0, StatSoft Inc.). Onset and termination of eye movements were determined when velocity exceeded a threshold of $50^{\circ} / \mathrm{s}$. Reaction time (RT) was calculated as the time from target appearance to saccade onset in saccade trials. Saccade trials were considered to be incorrect if subjects broke fixation during the instruction cue presentation, made no saccade after target appearance, made a correct response with RT below 100 ms (i.e., anticipatory) or above $1000 \mathrm{~ms}$, or made a direction error (i.e., made a first eye movement toward the target location in antisaccade trials, or away from the target location in prosaccade trials). Neutral fixation trials and catch trials where participants failed to maintain fixation were scored as incorrect. All these incorrect trials were discarded from the fMRI analyses. Table 2 depicts the number of correctly performed trials per age group that was finally used in statistical analyses after both behavioral and fMRI preprocessing. Direction errors were however kept as a measure of task performance (i.e., accuracy; Dyckman et al., 2007; Ethridge et al., 2009; Hutton and Ettinger, 2006; Luna et al., 2008; McDowell et al., 2008; Munoz and Everling, 2004). Saccades directed to the right or left target were pooled together as there was no main effect of target location for RT or direction error rate (repeated measures ANOVAs, $p>.05)$. One-way ANOVAs were performed to compare saccade RT

Table 2

Correctly performed trials used in final fMRI analyses.

\begin{tabular}{lllll}
\hline & & $8-12$ years & $13-17$ years & $18-25$ years \\
\hline \multirow{2}{*}{ Anticatch } & Total number & 797 & 741 & 1027 \\
& Mean (SD) & $25.7(12.3)$ & $29.6(14.3)$ & $44.6(11)$ \\
Procatch & Total number & 767 & 690 & 1021 \\
& Mean (SD) & $24.7(11)$ & $27.6(14.1)$ & $44.4(10.5)$ \\
Antisaccade & Total number & 1486 & 1530 & 2005 \\
& Mean (SD) & $47.9(27.1)$ & $61.2(26.4)$ & $87.2(19)$ \\
Prosaccade & Total number & 1717 & 1596 & 1965 \\
& Mean (SD) & $55.4(26.3)$ & $63.8(26.9)$ & $85.4(19.6)$ \\
Fixation & Total number & 2129 & 1894 & 2327 \\
& Mean (SD) & $68.7(26.1)$ & $75.8(26)$ & $101.2(21.7)$ \\
\hline
\end{tabular}

SD: standard deviation. and direction errors across children, adolescents and adults. Significant main effects of age group were examined further by post-hoc Tukey HSD (honestly significant difference) tests. Age-related changes in saccade performance were also examined using an inverse best-fitting regression model (Fig. 2), consistent with previous studies (Luna et al., 2004; Ordaz et al., 2010).

\section{fMRI data analysis}

Data were analyzed using Brain Voyager QX (Version 2.3; Brain Innovation, Maastricht, The Netherlands).

\section{Preprocessing}

Each scan was first visually inspected for quality assurance to detect any abrupt head motion and/or artifacts by watching time course movies. Based on the movies, data sets from fifteen participants ( 8 males, 2 females, aged 8-12 years; 4 males, 1 female, aged 13-17 years) were deemed not usable and thus eliminated from further analysis. Motion correction was applied to the remaining 416 time-series (148 in children, 126 in adolescents, 142 in adults) using a rigid body algorithm with trilinear interpolation within-run. Six movement parameters ( 3 translation parameters and 3 rotation parameters in $\mathrm{x}, \mathrm{y}, \mathrm{z}$ planes) were obtained from this realignment procedure. A root mean square value was calculated for each run across frames and across the three $\mathrm{x}, \mathrm{y}$, and $\mathrm{z}$ dimensions for each subject and for translation and rotation separately. Mean translation ranged between 0.025 and $0.82 \mathrm{~mm}$ across all subjects and mean rotation ranged from 0.016 to $0.78^{\circ}$, which was below our a priori cutoff of $2(\sim 2 / 3$ voxels). Root mean square values were averaged across runs within individuals and means were subjected to Pearson correlation analyses. There was no significant correlation between translation and age $(r=-0.046, p=$ $0.684)$, or rotation and age $(r=-0.193, p=0.089)$. As a check, we looked back at the files from the 15 subjects we eliminated following data quality assurance (see above). Motion correction analysis confirmed our decision: the output still showed evidence of large and abrupt motion, with movement exceeding 1 voxel. Next, slice scan time correction with cubic spline interpolation was applied to each run, followed by temporal filtering (high-pass filter with cut-off of 2 cycles per run and linear trend removal). Functional data were superimposed on anatomical images and normalized to Talairach space. Importantly, this stereotactic space has been validated for use in children 7 years-old and older, and the feasibility of comparing BOLD responses directly across development in this common atlas space and across different vascular territories well established (Brown et al., 2005; Burgund et al., 2002; Church et al., 2010; Kang et al., 2003; Wenger et al., 2004). Finally, functional images were spatially smoothed using a Gaussian kernel of $4 \mathrm{~mm}$ full-width at half-maximum.

\section{Statistical analysis}

The preprocessed fMRI data for each run and each participant were analyzed using the deconvolution design matrix model in Brain Voyager. This general linear model does not make any assumption about the shape of the BOLD response, which has been successfully validated in studies using rapid event-related designs (Miezin et al., 2000; Ollinger et al., 2001a,b). For each event type, a series of 13 predictors was defined covering a period of $20 \mathrm{~s}$ locked to trial onset, providing an estimate of the event-related BOLD response at each of the 13 time points, i.e., every $\sim 1.54 \mathrm{~s}$ (corresponding to $\sim 1$ $\mathrm{TR}$ ). This resulted in an estimated time course spanning 13 time points per voxel and per event type. Five event types were modeled: correct catch trials (pro, anti), correct saccade trials (pro, anti) and all incorrect trials, resulting in 65 regressors ( 5 trial types $\times 13$ time points) entered into the design matrix. Importantly, this analysis allowed us to examine correctly performed trials separately from incorrect trials, and thus determine developmental differences in 

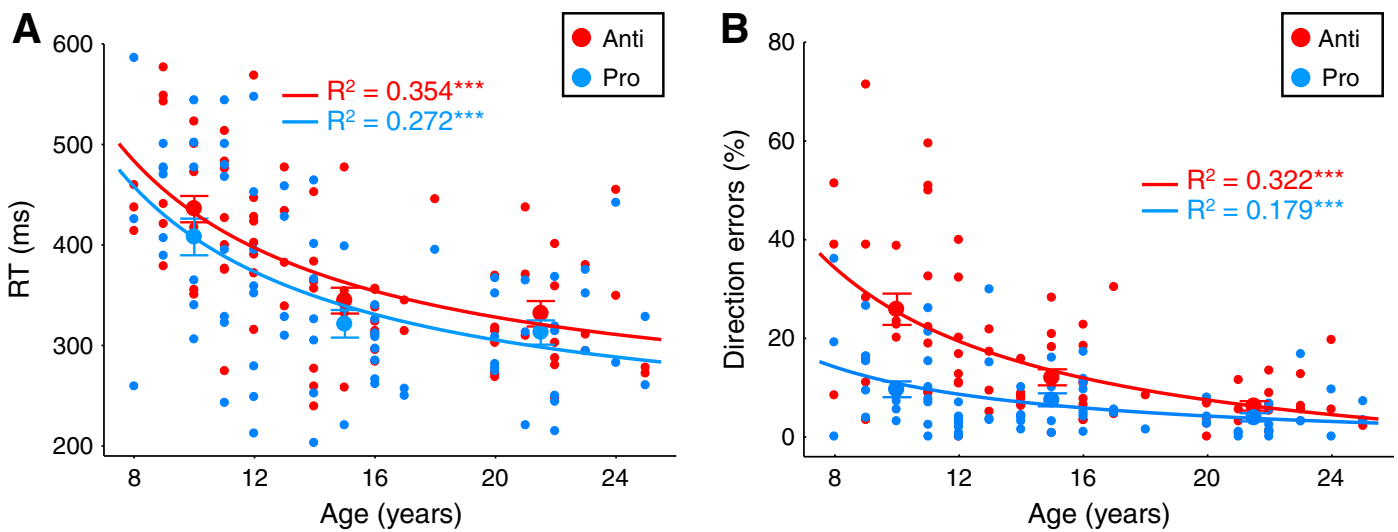

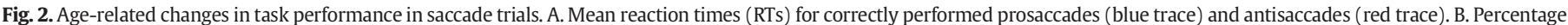

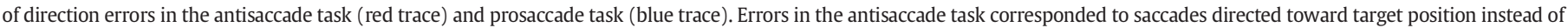

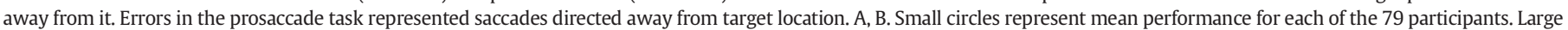

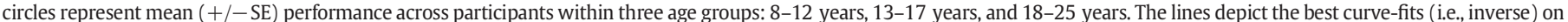
saccade parameters by age; ${ }^{* * *} p<0.001$.

BOLD responses when the same behavioral response (i.e., correct) was being generated by the three age groups. The total and mean numbers of correct trials for children, adolescents, and adults are presented in Table 2. Incorrect trials were excluded from the analyses but were separately modeled as a predictor of no interest to account for any variance in the BOLD signal associated with these errors (Brown et al., 2007; Murphy and Garavan, 2004). The six motion parameters were also included as nuisance factors in the model. The estimated BOLD response associated with neutral fixation trials was used as implicit baseline. Data were processed using a Z-transformation. The event-related parameter estimates were submitted to group analyses using a random-effects general linear model.

Regions of interest analyses. Our study is hypothesis-driven and did not include exploratory analyses across the whole brain. We focused on region of interest (ROI) analyses in five core regions known to be recruited by children, adolescents and adults (for reviews, Luna et al., 2008, 2010; McDowell et al., 2008): the frontal eye field (FEF), a key oculomotor area, the supplementary eye field (SEF) and the parietal eye field (PEF) that are two other regions consistently recruited during saccade generation, and the dorsolateral prefrontal cortex (DLPFC) and the anterior cingulate cortex (ACC) that are both implicated in top down executive control. ROIs were defined using both anatomical criteria and functional constraints.

Anatomical boundaries. The FEF was located around the junction of the precentral sulcus and the superior frontal sulcus on each hemisphere (Curtis et al., 2005; Manoach et al., 2007; Paus, 1996). The SEF was located in the dorsomedial frontal cortex in and around the paracentral sulcus, superior to the cingulate sulcus (Curtis et al., 2005; Manoach et al., 2007). The PEF was localized to the intraparietal sulcus defined as dividing the superior and inferior parietal lobules (Curtis and Connolly, 2008; Curtis and D'Esposito, 2003; Geier et al., 2010; Manoach et al., 2007). The DLPFC was localized in the middle frontal gyrus (Brown et al., 2007; Pierrot-Deseilligny et al., 2004; Velanova et al., 2008). The ACC was defined as the region in or below the cingulate sulcus, anterior to the anterior commissure (Curtis et al., 2005; Paus et al., 1993; Pierrot-Deseilligny et al., 2004).

Functional constraints. First, for each group (children: 8-12 years, adolescents: $13-17$, adults: $18-25$ ), we performed a general contrast all correct saccade trials $>$ fixation baseline at time points 5, 6, and 7, across participants. This time window was chosen from a preliminary inspection of the event-related time courses related to saccade trials because it encompassed maximal activation from trial start and accounted for both preparation and execution time intervals across various brain regions. The three age group-level contrast maps were thresholded at $p<0.05$, corrected at the $p<0.05$ level for multiple comparisons using a Monte Carlo simulation that required a minimum of 12 voxels. This general contrast highlighted the brain network involved in saccade generation while being both unbiased to differences between task types (pro, anti) and independent of our contrasts of interest (i.e., task preparation and task execution) (Kriegeskorte et al., 2009; Poldrack and Mumford, 2009). It confirmed that all three age groups showed similar spatial activation, in agreement with previous developmental studies (Luna et al., 2001; Velanova et al., 2008). Second, to select the ROIs independently of the effect of age (Kriegeskorte et al., 2009; Luna et al., 2010; Poldrack and Mumford, 2009), the individual contrast maps of all 79 participants were combined. Beta contrast images were obtained for each individual and then averaged to obtain a group beta contrast map, with an extent threshold of 12 voxels. In this combined group map (Fig. 3), within the predetermined anatomical boundaries described above, each ROI was selected consisting in a cubic cluster of activation containing the most significant 125 voxels. This resulted in two labels, one in each hemisphere, for the FEF, PEF, DLPFC and ACC, and one cluster for the SEF (Table 3).

From these functional clusters, we extracted the mean BOLD response estimates averaged across the 125 voxels, for each participant treated as a random effect, and for each of the four events of interest (catch: pro, anti; saccade: pro, anti). These averaged estimated BOLD responses were then used to study the age-related changes in instruction-related activation, reflecting prosaccade or antisaccade preparation, and in target-related activation, reflecting prosaccade or antisaccade execution. Saccade trials contained both preparation and execution epochs (Fig. 1A). In catch trials, a target was never presented (Fig. 1B). These catch trials were thus used to assess preparatory activation, without being contaminated by any execution-related process. Specifically, preparatory activation was measured with the contrast catch trials $>$ fixation baseline. Executionrelated activation was isolated by subtracting the activation associated with the catch trials (catch > fixation baseline) from the activation associated with the saccade trials (saccade $>$ fixation baseline). All the activation contrasts were performed for prosaccade and antisaccade tasks separately. Given that catch trials did not contain a peripheral target, preventing from assessing preparatory activation according to target location (right or left) and saccade direction, BOLD responses in the FEF, PEF, DLPFC and ACC were averaged across both hemispheres.

Effects of age across development. In a first step, the estimated BOLD response time courses associated with task preparation and task execution derived from the FEF, SEF, PEF, DLPFC and ACC were analyzed by 


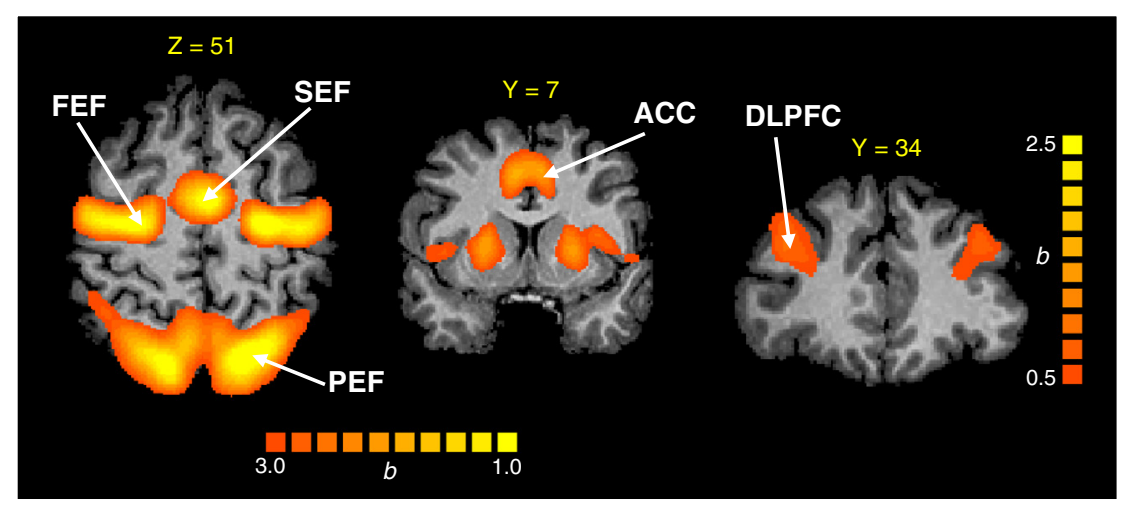

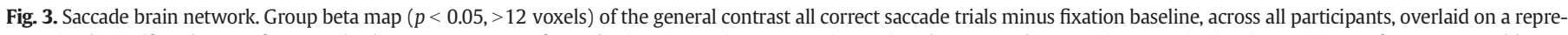

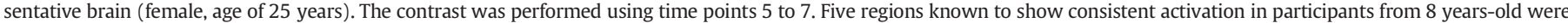

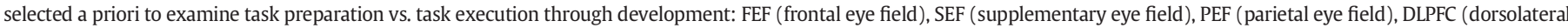
prefrontal cortex), and ACC (anterior cingulate cortex). Right side of image corresponds to left brain.

repeated measures ANOVAs with time (1-13 time points) as a withinsubject factor in each age group separately (children, adolescents, adults). This approach was similar to Brown et al.'s developmental study and was a crucial initial step to determine whether BOLD signal modulated significantly in the 5 ROIs during task preparation and execution for each age group. A significant effect of time indicated that the hemodynamic response was not a flat line across the 13 time points and that there was significant activation (Brown et al., 2005; Geier et al., 2010). In other words, a given ROI showing a main effect of time was interpreted as being recruited. All ANOVAs were corrected for sphericity using Greenhouse-Geisser correction and the levels of significance reported were therefore corrected values.

In a second step, one-way ANOVAs across the three age groups were performed to examine developmental differences in BOLD response during task preparation vs. task execution, for prosaccade and antisaccade tasks separately. Significant main effects of age group were then examined by post-hoc Tukey HSD tests. Mean of parameter estimates from time points 5 to 6 relative to trial onset was used to examine the ROI activation associated specifically with task preparation during task instruction (Fig. 4A; Fig. 6, left panels). This epoch was chosen a priori because it best represented peak activation during catch trials across ROIs and age groups. Mean of parameter estimates from time points 6 to 7 relative to trial onset was used to examine the ROI activation associated specifically with task execution after target appearance (Fig. 4B; Fig. 6, middle panels). The execution-related epoch was shifted by $1.5 \mathrm{~s}$ later relative to the preparation-related epoch because the peripheral target that triggered the prosaccade or antisaccade response in saccade trials appeared $1.5 \mathrm{~s}(\sim 1 \mathrm{TR})$ after the cue instruction (Fig. 1A). This

Table 3

Regions of interest (ROIs).

\begin{tabular}{lrrll}
\hline Region & \multicolumn{1}{c}{$\mathrm{x}$} & $\mathrm{y}$ & $\mathrm{z}$ & Beta \\
\hline Right FEF & 28 & -12 & 48 & 3.38 \\
Left FEF & -28 & -13 & 49 & 3.55 \\
SEF & -2 & -4 & 54 & 3.58 \\
Right PEF & 15 & -71 & 48 & 3.57 \\
Left PEF & -20 & -65 & 48 & 3.87 \\
Right DLPFC & 35 & 31 & 33 & 1.14 \\
Left DLPFC & -34 & 31 & 36 & 1.16 \\
Right ACC & 5 & 7 & 40 & 2.05 \\
Left ACC & -8 & 7 & 40 & 1.79 \\
\hline
\end{tabular}

ROIs corresponded to cubic clusters containing the 125 most significant voxels centered around peak activation in the general contrast all correct saccades $>$ fixation baseline across all participants (depicted in Fig. 3). Talairach coordinates (x, y, z) and beta value at peak activation are shown. approach is similar to previous saccade studies using two separate epochs to examine preparation vs. execution (Brown et al., 2007, 2008; Cameron et al., 2012; Hakvoort Schwerdtfeger et al., 2013).

Adults had significantly more correct trials than both adolescents and children who did not differ from each other (one-way ANOVAs, ps $<0.001$; Table 2), which may contribute to developmental differences in activation. Significant effects of age group were thus further explored by ANOVAs covarying the number of trials used for the activation contrasts (catch and fixation trials for preparation-related activation; saccade, catch and fixation trials for execution-related activation; see end of Regions of interest analyses section).

For all analyses, effects were considered significant at an alpha of 0.05

\section{Results}

\section{Task performance}

Regression analyses (Fig. 2) revealed that reaction times for both correct prosaccades $\left(F_{1,78}=28.8, p<0.001, R^{2}=0.272\right)$ and antisaccades $\left(F_{1,78}=42.1, p<0.001, R^{2}=0.354\right)$, as well as direction errors (i.e., unwanted prosaccades) in the antisaccade task $\left(F_{1,78}=36.5\right.$, $p<0.001, R^{2}=0.322$ ), decreased steeply from childhood to late adolescence, while performance tended to stabilize through adulthood. One-way ANOVAs for reaction times revealed main effects of age group for both prosaccade $\left(F_{2,76}=11.9, p<0.0001\right)$ and antisaccade $\left(F_{2,76}=20.2, p<0.000001\right)$ tasks. Post-hoc Tukey HSD tests indicated that children showed longer prosaccade and antisaccade reaction times compared to their elders ( $p s<0.001$ ), while performance in adolescents and adults did not differ significantly ( $p s>0.78$ ). There was also a main effect of age group for direction errors in the antisaccade task $\left(F_{2,76}=18.6, p<0.000001\right)$, children making more errors than adolescents and adults (post-hoc Tukey HSD tests: $p s<0.001$ ). As expected, participants were overall slower to respond correctly in the antisaccade task than the prosaccade task (main effect of task: $\left.F_{1,78}=15.1, p<0.001\right)$. Moreover, most direction errors (75\%) were corrected by a corrective saccade to the appropriate location. Importantly, the rate of correction did not covary with age (Pearson correlation $r=0.041, p=0.723$ ), suggesting that the higher percentage of direction errors in younger participants (Fig. 2B) was not due to a misunderstanding or non-compliance of the task instructions for the antisaccade task, but rather to an inability to efficiently inhibit the automatic response to the target.

For comparison, we also examined the rate of errors (i.e., unwanted antisaccades) in the prosaccade task (Fig. 2B). As expected, participants on average made fewer errors in the prosaccade task than the 

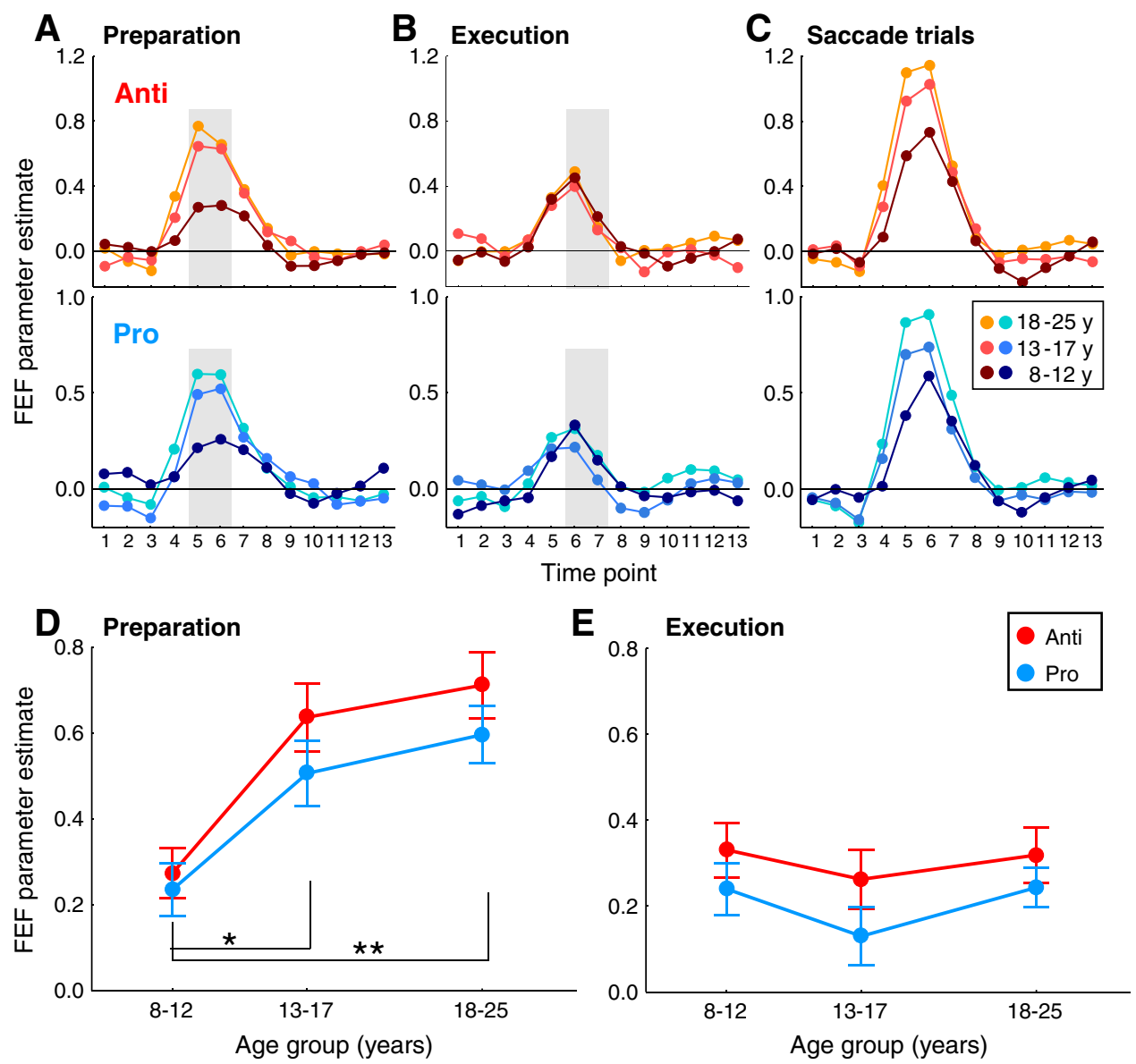

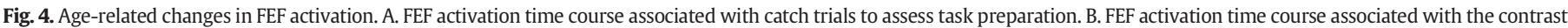

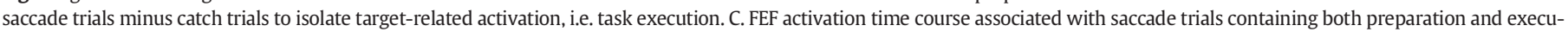

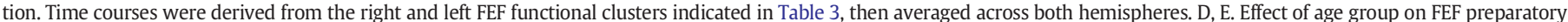

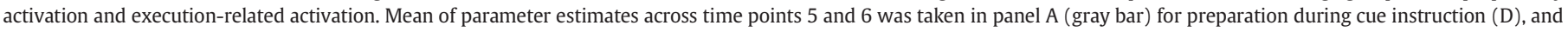

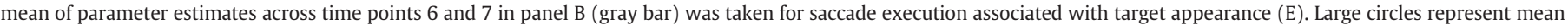

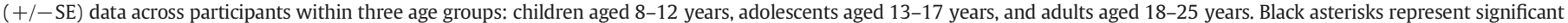
differences between children and the two other groups for both saccade tasks (post-hoc Tukey HSD tests following one-way ANOVAs). ${ }^{*} p<0.05 ;{ }^{* *} p<0.01$; others: non-significant.

antisaccade task ( $7.34 \pm 0.83 \%$ vs. $15.8 \pm 1.7 \%$, main effect of task: $\left.F_{1,78}=23.6, p<0.001\right)$. The rate of errors observed on prosaccade trials was not surprising given that prosaccade and antisaccade trials were interleaved in our fMRI design, and not performed in separate blocks of trials (Cherkasova et al., 2002; Ethridge et al., 2009). There was a main effect of age group $\left(F_{2,76}=4.28, p<0.05\right)$, children making more errors in the prosaccade task than adults (Tukey HSD test, $p=0.013$ ).

In sum, these fMRI behavioral results successfully replicate previous behavioral studies (Fischer et al., 1997; Klein and Foerster, 2001; Kramer et al., 2005; Luna et al., 2004; Munoz et al., 1998; Ordaz et al., 2010), allowing the examination of the role of task preparation in these behavioral improvements.

\section{Brain activation during task preparation vs. execution}

Fig. 3 depicts the brain network associated with saccade generation (prosaccades and antisaccades pooled together) across all participants, replicating many previous studies (for review, McDowell et al., 2008). Within this saccade network, five core regions of interest (ROIs) were selected for quantitative analysis: the frontal eye field (FEF), the supplementary eye field (SEF), the parietal eye field (PEF), the dorsolateral prefrontal cortex (DLPFC) and the anterior cingulate cortex (ACC). These ROIs were selected because of consistent recruitment by children, adolescents and adults from past studies (for reviews,
Luna et al., 2008, 2010; McDowell et al., 2008). Table 3 provides the location of peak voxels within the selected ROIs, which is consistent with prior adult (e.g. Agam et al., 2010; Brown et al., 2007; Connolly et al., 2002; DeSouza et al., 2003; Ettinger et al., 2008; Ford et al., 2005; Luna et al., 1998) and developmental (Geier et al., 2010; Padmanabhan et al., 2011; Velanova et al., 2008) fMRI studies. The main question we asked here was whether brain activity in these regions, as measured by the blood oxygen level dependent (BOLD) response estimate, was different across developmental age groups when making correct prosaccades and antisaccades during two separate epochs of saccade generation: 1 ) the presentation of the instructional cue, reflecting task preparation required before target onset and 2) the appearance of the peripheral target, reflecting execution of the prosaccade or antisaccade in the correct direction. Preparatory activation was measured with catch trials that contained only the task instruction, and no target presentation (Fig. 1B). Execution-related activation was assessed by subtracting the activation associated with catch trials from the activation associated with saccade trials (see Regions of interest analyses section).

\section{FEF}

Relationship between FEF activation and age. Table 3 provides the location of maximal activation (125 voxels) for the left (Talairach coordinates: peak at $-28,-13,49)$ and right $\operatorname{FEF}(28,-12,48)$. The averaged event-related BOLD response estimates were extracted from these two FEF clusters for each participant and then averaged across both 
hemispheres. The time courses of FEF activation locked to trial onset (13 time points $=20 \mathrm{~s}$ ) are illustrated for the three age groups ( $8-12$ years, 13-17 years, $18-25$ years) in Figs. 4A-C. For the three age groups, separate repeated measures ANOVAs with time (1-13 time points) as within-subject factor revealed that the FEF showed significant activation for both task preparation (Fig. 4A) and task execution (Fig. 4B), as indicated by main effects of time ( $p s<0.005$ for preparation, $p s<0.05$ for execution). In other words, children, adolescents, and adults recruited the FEF to prepare and execute the appropriate prosaccade or antisaccade response.

A notable result was that for both prosaccade and antisaccade tasks, execution-related activation was indistinguishable between the three age groups (Fig. 4B), while in sharp contrast, FEF preparatory activation heightened from children to adults (Fig. 4A). To further explore these developmental effects, we performed one-way ANOVAs across age groups, using mean activation across time points 5 and 6 for instruction-related preparation (Fig. 4A, gray box), and across time points 6 and 7 for target-related execution (Fig. 4B, gray box; for details see Effects of age across development section). One-way ANOVAs revealed main effects of age group for preparatory activation for both prosaccade $\left(F_{2,76}=8.01, p<0.001\right)$ and antisaccade $\left(F_{2,76}=11.6, p<0.0001\right)$ tasks (Fig. $4 D$ ). Post-hoc Tukey HSD comparisons indicated that preparatory activity was lower in children compared to adolescents $(p s<0.05)$ and adults ( $p s<0.01$ ) whereas no significant difference was found between adolescents and adults ( $p s>0.6$ ). The significant effect of age group for preparatory activation remained when covarying the number of catch trials and fixation trials for both prosaccade $(p<0.01)$ and antisaccade $(p<0.005)$ tasks, with no significant effect of the covariates ( $p s>0.08$ ). On the contrary, no main effects of age group were found for execution-related activation (Fig. 4E) in the prosaccade $\left(F_{2,76}=1.11, p=0.333\right)$ or antisaccade $\left(F_{2,76}<1\right)$ task.

In sum, FEF activation reflecting task preparation, not task execution, was most sensitive to developmental age groups, with children showing reduced activation compared to adolescents and adults.

Relationship between FEF preparatory activation and task performance. Past adult fMRI (Connolly et al., 2005) and monkey single-neuron recording (Everling and Munoz, 2000) studies revealed that higher preparatory activity in the FEF correlates with shorter saccade reaction times. We tested here whether we would reproduce these results. We found that across all participants both prosaccade RT ( $r=$ $-0.312, p=0.005)$ and antisaccade RT $(r=-0.512, p<0.001)$ decreased significantly with increasing preparatory activation. Partial correlations controlling for age indicated that these relationships were maintained for the antisaccade task $(r=-0.354, p=0.001)$, or reduced to a trend for the prosaccade task $(r=-0.186, p=$ 0.102 ). When considering each age group separately (Fig. 5A), the negative relationship between antisaccade RT and FEF preparatory activation was significant in adults $(r=-0.469, p=0.024)$, marginally significant in adolescents $(r=-0.371, p=0.068)$, but lacking in children $(r=-0.186, p=0.316)$. For prosaccade preparation (Fig. 5B), a significant negative correlation between RT and FEF activation was observed in adults $(r=-0.503, p=0.014)$ but not in adolescents $(r=-0.298, p=0.148)$ or children $(r=-0.089$, $p=0.633$ ).

Everling and Munoz (2000) also found a correlation between levels of preparatory activity in FEF neurons at the location where the target was represented and the occurrence of direction errors in the antisaccade task in monkey. Although our protocol was not ideal to dissociate preparatory activation related to incorrect antisaccade trials from correct antisaccade trials, we checked whether we could nevertheless find a correlation between preparatory activation as measured by catch trials and the rate of direction errors on antisaccade trials in our study. The frequency of direction errors across all participants decreased with increasing FEF preparatory activation $(r=-0.33, p=0.003)$.
A

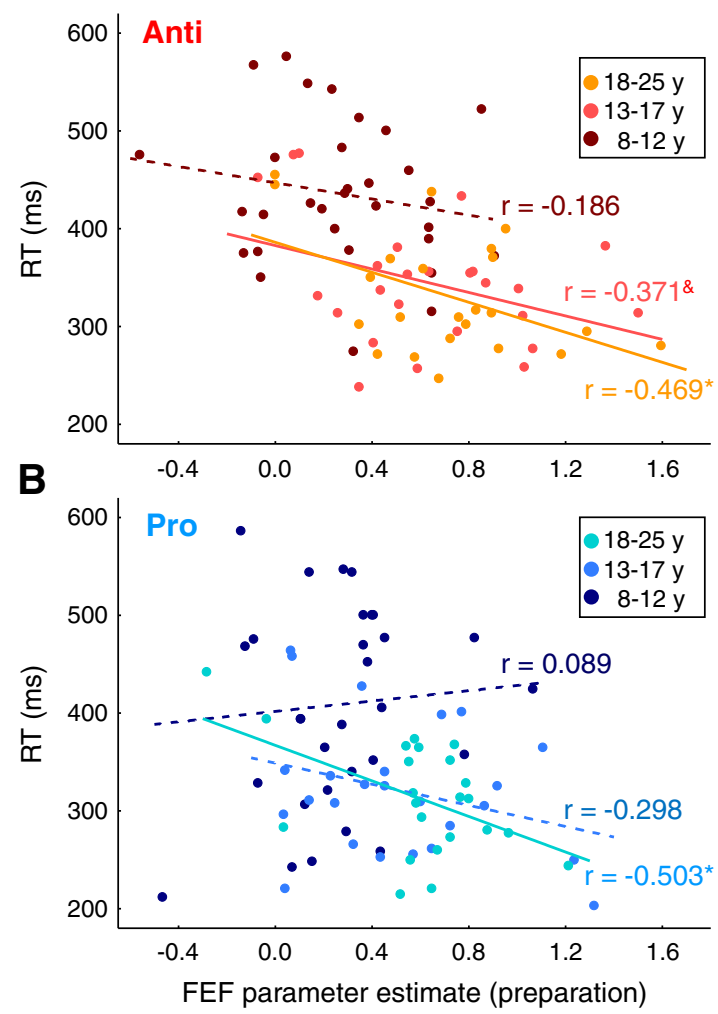

Fig. 5. Relationship between task performance and FEF preparatory activation. Preparatory activation derives from the mean across time points 5 and 6 in the activation time courses associated with catch trials in Fig. 4A (gray box). A. Correlation across participants within each age group (children, adolescents, adults) between reaction time (RT) and FEF preparatory activation for the antisaccade task. B. Correlation across participants within each age group (children, adolescents, adults) between reaction time (RT) and FEF preparatory activation for the prosaccade task. ${ }^{*} p<0.05 ; \& p=0.068$; others: non-significant.

However, this relationship was lost after controlling for age $(r=$ $-0.119, p=0.299$ ). Moreover, no correlation was observed in each age group separately ( $p s>0.1$ ).

In short, our data suggest overall that levels of FEF preparatory activation reflecting task preparation can predict how fast participants initiate correct saccades.

\section{SEF and PEF}

SEF and PEF are two other brain regions consistently recruited during saccade generation and interconnected with the FEF. Table 3 provides the location of maximal activation for these two brain areas. The activation times courses associated with saccade preparation and execution in the SEF and PEF are depicted in Figs. 6A and B, respectively. Both ROIs showed significant activation for both task preparation and execution in the three age groups (main effect of time: $p s<0.05 ; p=0.056$ in adolescents for PEF activation during prosaccade task preparation). Thus, children, adolescents and adults recruited the SEF and PEF during both task preparation and execution.

Here again (Figs. 6A, B), the magnitude of BOLD responses looked similar across age groups for task execution, whereas it heightened from children to adults for task preparation. For the SEF (Fig. 7A), there was indeed a main effect of age group for preparatory activation for both prosaccade $\left(F_{2,76}=4.68, p=0.012\right)$ and antisaccade $\left(F_{2,76}=6.83, p=0.002\right)$ tasks. Preparatory activation in children was reduced compared to adolescents and adults, while adolescents and adults did not differ from each other. These developmental differences remained when covarying the number of catch and fixation 
Preparation

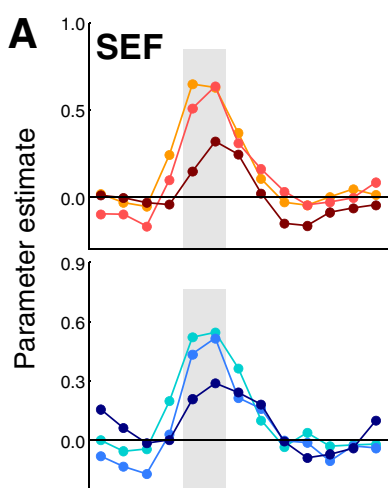

B

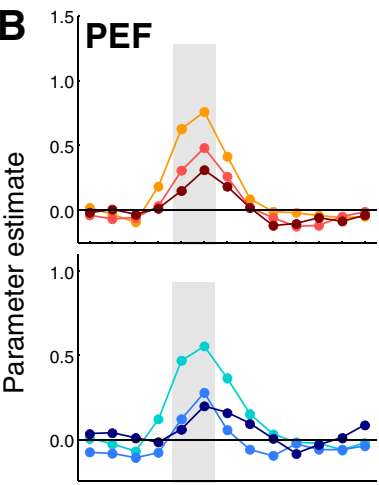

C
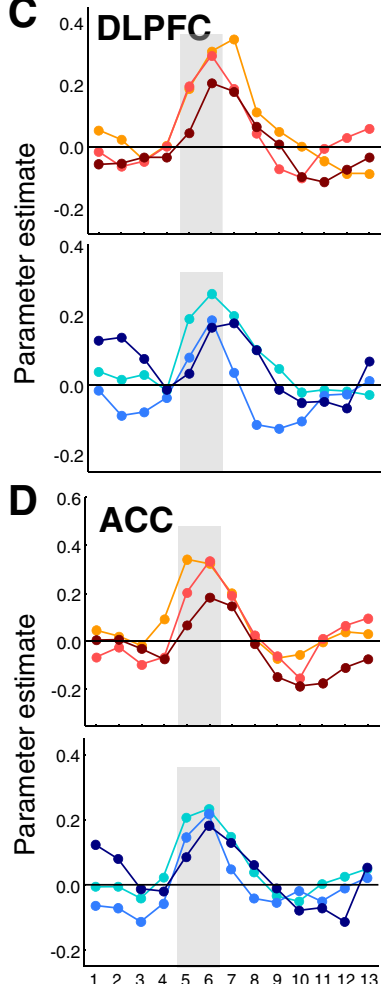

Execution
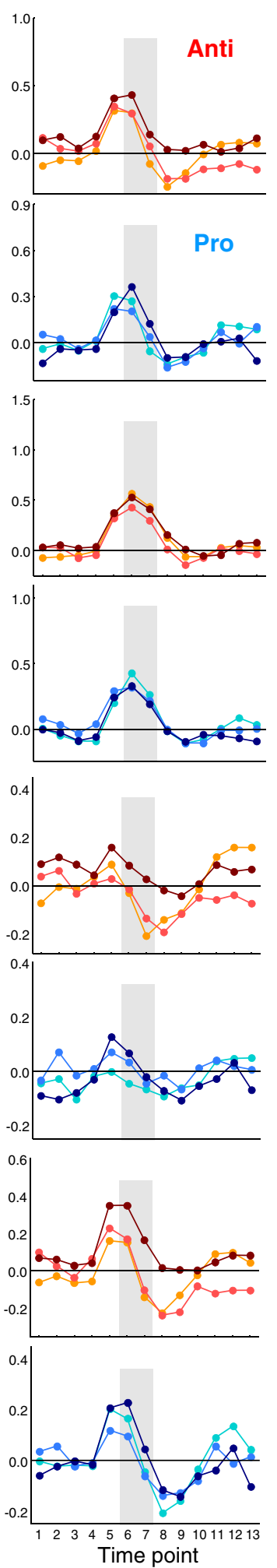

Saccade trials
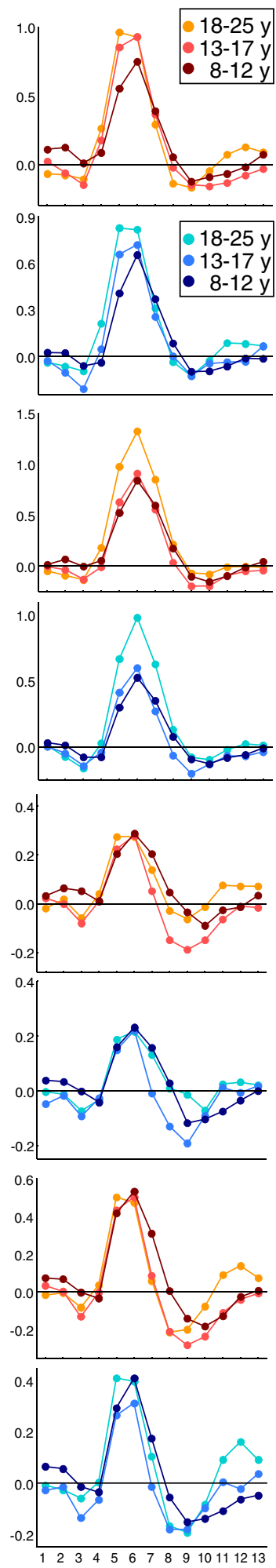

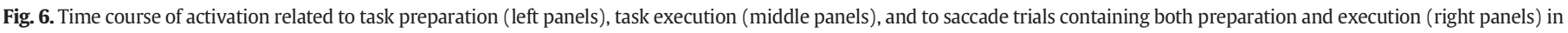

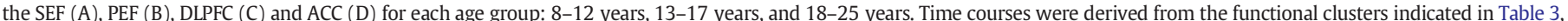

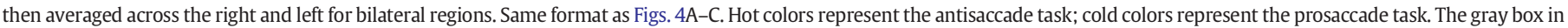

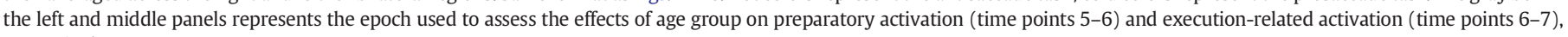
respectively.

trials for both prosaccade $(p=0.052)$ and antisaccade $(p<0.05)$ tasks, with no significant effect of the two covariates ( $p s>0.5$ ). For the PEF (Fig. 7C), the magnitude of preparatory activation also increased with age group for both prosaccade $\left(F_{2,76}=9.88, p<0.001\right)$ and antisaccade $\left(F_{2,76}=10.8, p<0.0001\right)$ tasks. Both children and adolescents showed reduced preparatory activation compared to adults but did not differ 

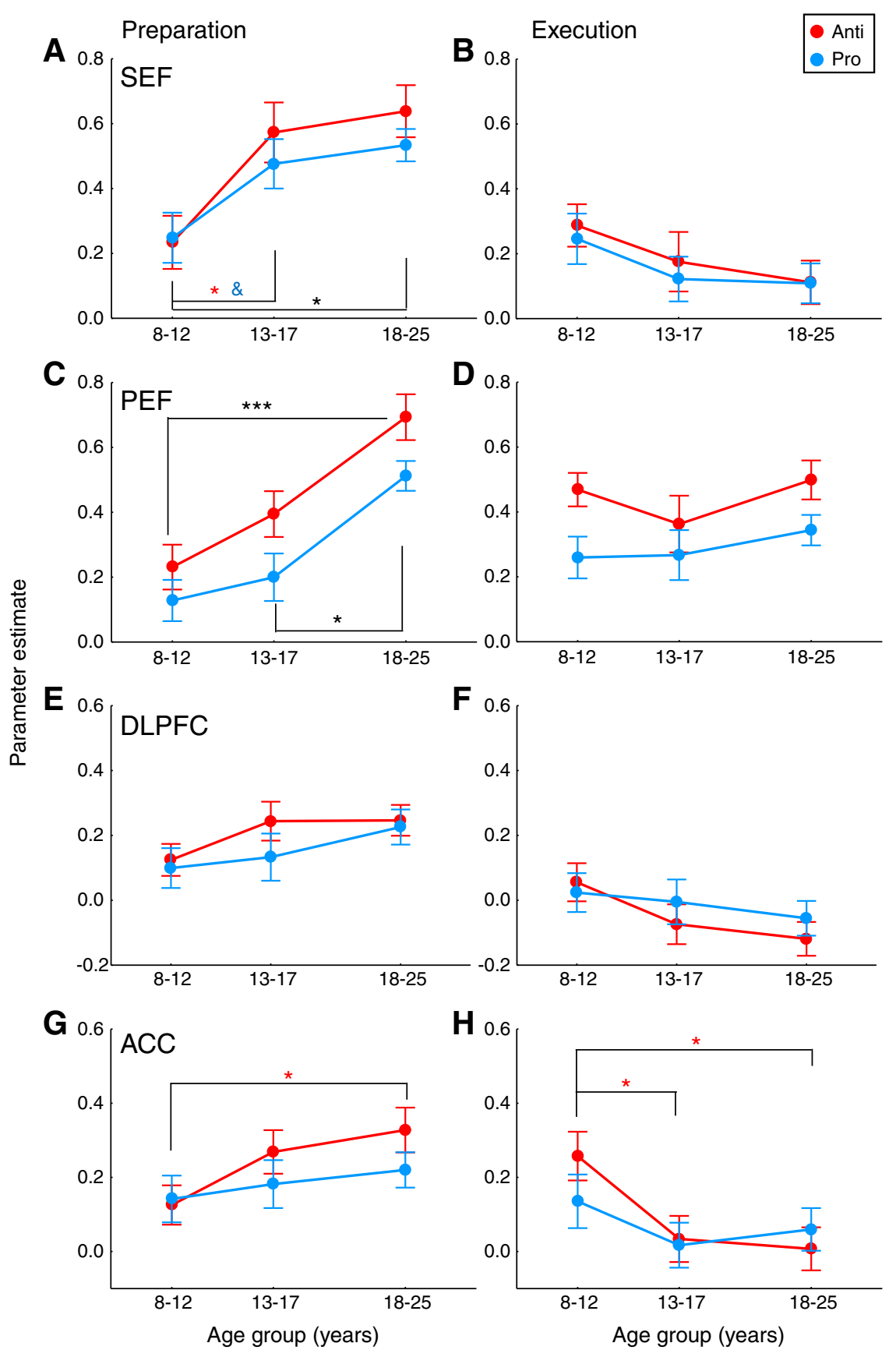

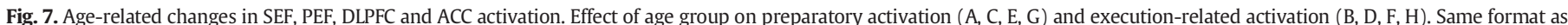

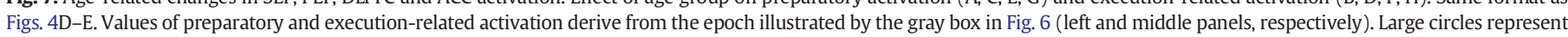

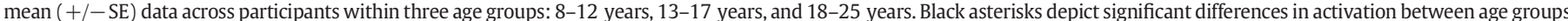

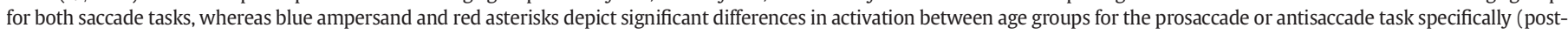
hoc Tukey HSD tests). ${ }^{*} p<0.05 ;{ }^{* *} p<0.01 ;{ }^{* * *} p<0.001 ; \& p=0.061$; others: non-significant.

from each other. This developmental increase in preparatory activation remained when covarying the number of catch and fixation trials for both prosaccade $(p<0.05)$ and antisaccade $(p<0.01)$ tasks, the covariates showing no significant effect $(p s>0.3)$. On the contrary, no significant effect of age group was found for prosaccade execution in the $\operatorname{SEF}\left(F_{2,76}=1.17, p=0.314\right)$ or $\operatorname{PEF}\left(F_{2,76}<1\right)$, or for antisaccade execution in the $\operatorname{SEF}\left(F_{2,76}=1.44, p=0.242\right)$ or PEF $\left(F_{2,76}=1.08, p=0.344\right.$; Figs. 7B, D $)$.

In sum, similarly to the FEF, SEF and PEF activation reflecting task preparation, not task execution, heightened with development.

\section{DLPFC and ACC}

Next, we interrogated the DLPFC and ACC, two areas involved in executive control and critical for antisaccade performance. Table 3 provides the location of maximal activation for these two brain areas. The activation times courses associated with saccade preparation and execution in DLPFC and ACC are depicted in Figs. 6C and D, respectively. For the DLPFC (Fig. 6C), a main effect of time (1-13 time points) for preparatory activation was observed within each age group ( $p s<0.05)$, suggesting that children, adolescents and adults recruited the DLPFC during saccade preparation. For task execution, results were 
rather mixed. For the antisaccade task, activation was significant in adults (main effect of time: $F_{12,264}=8.35, p<0.001$ ) and marginally significant in adolescents $\left(F_{12,288}=2.13, p=0.057\right)$. For the prosaccade task, only a marginally significant effect of time was observed in children $\left(F_{12,360}=2.17, p=0.055\right)$. These mixed results were not surprising given the superior involvement of DLPFC in saccade preparation rather than execution according to human fMRI studies (Brown et al., 2007). One-way ANOVAs revealed no significant differences in DLPFC activation among age groups for prosaccade preparation $\left(F_{2,76}=1.02, p=0.367\right)$ or antisaccade preparation $\left(F_{2,76}=\right.$ $1.87, p=0.16$; Fig. $7 \mathrm{E})$, or for prosaccade execution $\left(F_{2,76}<1\right)$ or antisaccade execution $\left(F_{2,76}=2.51, p=0.09\right.$; Fig. $\left.7 F\right)$.

The ACC (Fig. 6D) exhibited significant activation for both task preparation and execution within each age group (main effect of time: ps $<0.05$ ), except in the adolescent group where the effect of time for prosaccade execution-related activation was reduced to a trend $\left(F_{12,288}=1.96, p=0.096\right)$. Thus the ACC was reliably recruited by children, adolescents and adults during saccade preparation. Antisaccade preparatory activation differed across age groups $\left(F_{2,76}=3.46, p<0.05\right)$, children showing lower levels of activation than adults (Fig. 7G). This effect of age group was lost when covarying the number of catch and fixation trials $(p=0.145)$, although the covariates showed no significant effect $(p s>0.4)$. Antisaccade execution-related activation also differed across age groups $\left(F_{2,76}=\right.$ $5.01, p<0.01)$, children showing increased activation compared to both adolescents and adults (Fig. 7H). This decrease in activation from children to adults did not remain when covarying the number of saccade, catch and fixation trials $(p=0.142)$, these covariates showing no significant effect ( $p s>0.08$ ). No age group effects were observed in the prosaccade task (Figs. 7G, H) for preparatory activation $\left(F_{2,76}<1\right)$ or execution-related activation $\left(F_{2,76}<1\right)$.

In sum, the DLPFC and ACC were consistently recruited during saccade preparation. Preparatory activation in the DLPFC did not differ among age groups. From children to adults, ACC activation increased for antisaccade preparation whereas it decreased for antisaccade execution. These opposite developmental effects in the ACC may be partly accounted for the number of trials included in fMRI analyses as indicated by the additional analyses that used the number of trials as a covariate.

\section{Discussion}

We examined fronto-parietal activity at two stages of saccade control (task preparation during instruction vs. task execution after target appearance) to test the hypothesis that preparatory processes contribute to the improvements in prosaccade and antisaccade performance from childhood to adulthood. The present findings provide strong support in favor of our hypothesis. Preparatory activation heightened from children to adults in the core oculomotor network composed of the FEF, SEF and PEF for both prosaccade and antisaccade tasks. The ACC also showed higher preparatory activation with increasing age for the antisaccade task, reinforcing its critical role in antisaccade cognitive control. In contrast, executionrelated activation did not change across age groups, except in the ACC where activation decreased from children to adults in the antisaccade task. Changes in ACC activation across age groups may be also partly due to the number of trials included per participant (see DLPFC and ACC section) and thus, cautions should be taken in the interpretations of these specific changes. At last, the DLPFC showed no age-related changes during saccade preparation or execution. Three important implications can derive from these results. 1) The data reinforce the crucial role of the core fronto-parietal network in saccade preparation, and extend its involvement during development. 2) Developmental improvements in both prosaccade and antisaccade performance are related to enhancements in preparatory processes associated with task instruction rather than execution processes associated with target appearance. In other words, developmental improvements in behavior control are supported by improvements in the ability to effectively preset goalappropriate brain systems. 3) Children may use compensatory execution-related processes to correctly perform the tasks.

\section{Improvements in task preparation across development}

Our neuroimaging findings provide new and direct evidence that developmental improvements in saccade performance are related to saccade preparation prior to target appearance, confirming and extending a behavioral study that manipulated the length of the preparatory period to study the role of preparation in development of antisaccade control (Ordaz et al., 2010). We found that the frontoparietal network including the FEF, SEF, PEF, DLPFC and ACC that is critical for saccade preparation before target appearance in adults (for review, McDowell et al., 2008) is also recruited by children and adolescents, but in a 'suboptimal' manner. Indeed, ANOVAs revealed that the magnitude of preparatory activation within these different areas (except the DLPFC) increased with development, suggesting that the core preparatory processes that are in place in children continue to undergo gradual enhancements through childhood and adolescence. Importantly, the age-related differences in preparatory activation were unlikely to be due to differences in fixation and/or stimuli properties. Fixation baseline activation did not significantly differ across age groups within the different ROIs, and no agerelated changes in activation were found during catch trials in primary visual cortex (not illustrated). A subset of electrophysiological studies supports our findings. The contingent negative variability, an electrophysiological index of task preparation, was reduced in children below around the age of 12 , and was related to a delayed recruitment of anterior-central areas including frontal motor areas (Bender et al., 2005; Flores et al., 2009; Jonkman, 2006; Klein and Feige, 2005). Moreover, a number of developmental fMRI studies using tasks requiring cognitive control revealed immature patterns of activation in children and adolescents compared to adults in the fronto-parietal cortical network including lateral prefrontal cortex, parietal cortex, anterior cingulate cortex, and pre-supplementary/ supplementary motor area (e.g., Bunge et al., 2002; Crone et al., 2006; Luna et al., 2001; Rubia et al., 2006; Velanova et al., 2008, 2009). Similarly to previous studies (Crone et al., 2006; Velanova et al., 2008, 2009), we found patterns of activation that were mature by adolescence in parallel to adult-like behavior performance, but also still immaturities in adolescence (here the PEF), which suggests continuing refinements into adulthood. Overall, we propose that a component of cognitive control that continues to improve through childhood and adolescence is the representation of task set: the ability to prospectively configure an upcoming task based on arbitrary rules (Bunge et al., 2005; Sakai, 2008).

The DLPFC was the only studied region that exhibited no age-related changes in preparatory activation. Structural maturation of the prefrontal cortex through childhood and adolescence (Gogtay et al., 2004 ) is thought to support maturation of cognitive control into adolescence (Luna and Sweeney, 2004). Actually, fMRI studies reported different developmental trajectories of DLPFC activation during inhibition tasks, which may depend on the type of task or design used. Some showed an increase in DLPFC activation from children to adults (Tamm et al., 2002), others a decrease (Casey et al., 1997; Durston et al., 2002; Velanova et al., 2008), and others showed non-linear changes (Luna et al., 2001). Our rapid interleaved design may have required higher vigilance and increased cognitive demands during the presentation of the instruction cue, such as enhanced reliance on inhibitory control, increased working memory for rules and for task set maintenance, and increased rule-based response selection demands. These processes have been shown to be associated with the DLPFC (e.g., Brown et al., 2007; Bunge, 2004; Crone et al., 2006; 
De Souza et al., 2003; Ford et al., 2005; Johnston and Everling, 2006; Jolles et al., 2011; Koval et al., 2011; Sakai, 2008). As a result, the DLPFC may have exerted tonic activity across the whole experiment in our study (Dyckman et al., 2007) and was thus engaged similarly across age groups. A developmental fMRI study also suggested that children (ages 8-13) and adults (ages 20-27) may show similar recruitment of regions involved in cognitive control, in particular the DLPFC, provided these regions reflect the maintenance, rather than the manipulation, of information in working memory (Wendelken et al., 2012).

Enhanced task preparation across development likely produced better task performance. We found that RTs correlated negatively with preparatory activation across all participants in the FEF, confirming previous studies in both humans (Connolly et al., 2005) and monkeys (Everling and Munoz, 2000). In other words, the more prepared the participants were, the faster they responded with the correct saccade after target appearance. These correlations were also found in adults and adolescents when examined separately, but not in children, reinforcing our conclusion that preparatory processes in children are immature. We also examined whether levels of FEF preparatory activation could predict the occurrence of direction errors, based on single neuron recordings in monkey FEF (Everling and Munoz, 2000). Higher preparatory activation correlated with lower rate of direction errors, but this significant relationship was lost after controlling for age. This indicates that the initial relationship between direction error rate and preparatory activation was probably due to age differences, the younger participants making more errors and having lower activation levels, and conversely for the adults. This negative result was not really surprising and should be interpreted with caution as preparatory activation was not taken from direction error trials directly, but from catch trials. Catch trials, which contained an instruction cue but no target presentation or saccade response, likely reflect general preparation or preparatory set: the readiness and/or intention to perform a given task, rather than preparation of a saccade in a specific direction (Curtis and Connolly, 2008). Consequently, they could predict how fast a participant may respond when a target eventually appears depending on the state of preparedness, but not if the subject will make a correct saccade or an error. A couple of fMRI studies in adults used long instruction periods ( $>6 \mathrm{~s}$ ) to dissociate activation related to response preparation from execution within correct and incorrect antisaccade trials, but reported contradictory results. Curtis and D'Esposito (2003), using eight possible target locations in their paradigm, found significant differences in FEF preparatory activation between correct antisaccade trials and direction errors, whereas Ford et al. (2005) did not. Future research is necessary to determine the role of the FEF in response inhibition during the instruction epoch in adults, and throughout development by designing a more suitable paradigm.

\section{Execution-related activity across development}

Execution-related activation did not reliably change across developmental age groups. These results revealed that, once the target appeared, younger participants had no overall difficulty correctly implementing the instruction or rule (look toward or away), or in the sensory-motor processing. Age group-related differences were however observed in the ACC where activation related to correct antisaccade execution decreased from children to adults. Brass and von Cramon (2002) suggested that, during target-related processing, the ACC is related to response inhibition and resolving response conflict. Here in the antisaccade task, there is a conflict between looking toward the target and looking away from it. It is possible that the ACC provides a supplementary signal in younger people to help resolving this response conflict after target appearance. This increased engagement in the youngest participants may thus reflect some strategy or compensatory mechanism for immature preparation and/or task difficulty in order to execute a correct antisaccade.

\section{Link to neurophysiological findings}

Presetting the fronto-parietal brain network prior to target appearance is particularly important for the antisaccade task for optimal performance, including the suppression of the unwanted competing prosaccade. This is commonly reflected in fMRI studies by higher BOLD signal for antisaccades than prosaccades prior to saccade execution in the FEF, PEF, SEF, ACC and DLPFC (Brown et al., 2007; Curtis and Connolly, 2008; DeSouza et al., 2003; Ford et al., 2005) although such differential activation in some of the areas can be affected by the context in which the two types of saccades are presented (i.e., blocked vs. interleaved designs; Dyckman et al., 2007). Higher activation in the FEF for antisaccade than prosaccade preparation is among the most consistent finding in the human fMRI literature (Brown et al., 2007; Connolly et al., 2002; DeSouza et al., 2003; Ford et al., 2005; Manoach et al., 2007). Moreover the role of FEF neurons in antisaccade and prosaccade generation has been well delineated (Everling and Munoz, 2000; Munoz and Everling, 2004), providing an interesting and sensitive groundwork to better interpret developmental fMRI results.

Single-neuron recordings revealed that saccade-related neurons in the FEF are strongly modulated by the antisaccade task by showing a lower level of preparatory activity, reduced target-related activity, and reduced saccade motor burst compared to the prosaccade task (Everling and Munoz, 2000). Fixation-related neurons in the FEF show the reverse pattern of activity during the preparation period and their activity falls to a minimum during target-related and motor response periods (Munoz and Everling, 2004). The reduction of preparatory activity in FEF saccade-related neurons for the antisaccade task, before target appearance, is necessary to prevent the initiation of the prosaccade and allow time for the antisaccade to be generated when the target appears. This reduced preparatory activity in FEF neurons seems paradoxical compared to the enhanced preparatory activation in the FEF reported in fMRI studies. Actually, the recordings by Everling and Munoz (2000) were from FEF layer $\mathrm{V}$ pyramidal neurons projecting to the superior colliculus (reflecting thus output signals), whereas the BOLD signal change is more reflective of the inputs to a given area and synaptic processing (Logothetis et al., 2001; Viswanathan and Freeman, 2007) including interneuron activity (Connolly et al., 2002; Ford et al., 2009). Altogether, the enhanced FEF activation for antisaccade preparation in fMRI may reflect heightened inhibition-related preparatory signals necessary for the suppression of the inappropriate automatic response to the target. In our study, the age-related changes in preparatory activity for the antisaccade task could reflect a development of these inhibition-related signals, leading to more and more successful antisaccades and thus less direction errors.

We reported earlier that FEF preparatory activity in saccade-related neurons in monkey (Everling and Munoz, 2000) and in human fMRI studies (Connolly et al., 2005) correlates negatively with saccade RTs, a result that we confirmed here. We interpret these results as reflecting motor preparation signals associated with planning the correct prosaccade or antisaccade. These motor preparation signals could also partly explain our developmental results. These signals may have lower levels in the youngest participants, explaining their longer saccade reaction times. With development, levels of these signals may become higher and more efficient, thereby leading to shorter reaction times.

In summary, neuron activity in the FEF prior to target appearance can be modulated by multiple signals among which inhibition-related signals required to suppress unwanted automatic responses and motor preparation signals for correct responses. Appropriate levels of these signals prior to target appearance are necessary to then generate a correct and fast response. FEF BOLD activation during task instruction might thus reflect these different preparatory signals. In sum, the patterns of preparatory activation in the FEF depicted in 
Fig. 4D could reflect the concurrent strengthening through childhood and adolescence of inhibition-related signals for suppression of incorrect saccades and motor preparation signals for correct saccades. Future studies with a more appropriate design are needed to be able to dissociate these two signals. Based on the current understanding of the nature of the BOLD signal change, these developmental modulations of preparatory signals could occur in the FEF by the interplay between saccade-related and fixation neurons, but also come from various input sources to the FEF, including the SEF (Amador et al., 2004), DLPFC (Johnston and Everling, 2006), ACC (Johnston et al., 2007), and indirectly from the basal ganglia (Watanabe and Munoz, 2010, 2011), which all show different preparatory sets for antisaccades and prosaccades. In addition, in the current study we identified age-related changes in the frontal and parietal cortical areas. The key-message is that developmental improvements in saccade performance are supported by developmental enhancements in presetting the core saccade brain circuit before target appearance. This functional maturation is further supported by brain structural development and refinements during childhood and adolescence in frontal and parietal cortices and basal ganglia, as well as strengthening of effective and functional connectivity between frontal and cortical or subcortical regions (Asato et al., 2010; Barnea-Goraly et al., 2005; Gogtay et al., 2004; Huttenlocher and Dabholkar, 1997; Hwang et al., 2010; Lenroot et al., 2007; Olesen et al., 2003; Snook et al., 2005; Sowell et al., 1999; Sowell et al., 2002). Synaptic pruning and myelination that continue into adolescence (Huttenlocher, 1990; Yakovlev and Lecours, 1967) may also contribute to optimal saccade performance by improving information processing times and optimizing the integration of distributed neural circuits. In sum, our study starts to dissect the sub-processes that may support the developmental improvements in saccade control by highlighting the importance of preparatory processes. While these cross-sectional comparisons provide important insights on developmental processes subserving cognitive control, longitudinal studies will be required to assess these changes within-participant and confirm these crosssectional results (Durston et al., 2006; Koolschijn et al., 2011).

\section{Conclusion}

We propose that developmental improvements in voluntary control of behavior are supported by developmental enhancements in presetting core brain regions for appropriate goals. The ability to prepare or anticipate for an action is particularly important in daily life where our dynamic environment contains various cues and rules that may all potentially guide our behaviors, and any maladaptive decision or choice made in a specific situation might have more or less detrimental consequences. This study suggests a potential avenue for the deficits in behavioral control that characterize various neurodevelopmental disorders (Norman et al., 2009; Sweeney et al., 2004; Toga et al., 2006).

\section{Funding}

This research was supported by the Canadian Institutes of Health Research (CIHR) grant MOP-97741. N.A. was supported by a postdoctoral award from the CIHR. D.P.M. was supported by the Canada Research Chair Program.

\section{Acknowledgments}

We are very grateful to the participants and families who took part in this study. We also thank Sharon David for outstanding technical assistance, Jason Gallivan for helpful discussion, and the members of the Munoz lab for comments on an earlier version of the manuscript.

\section{References}

Agam, Y., Joseph, R.M., Barton, J.J., Manoach, D.S., 2010. Reduced cognitive control of response inhibition by the anterior cingulate cortex in autism spectrum disorders. Neuroimage 52, 336-347.

Amador, N., Schlag-Rey, M., Shlag, J., 2004. Primate antisaccade. II. Supplementary eye field neuronal activity predicts correct performance. J. Neurophysiol. 91, 1672-1689. Asato, M.R., Terwilliger, R., Woo, J., Luna, B., 2010. White matter development in adolescence: a DTI study. Cereb. Cortex 20, 2122-2131.

Barnea-Goraly, N., Menon, V., Eckert, M., Tamm, L., Bammer, R., Karchemskiy, A., Dant, C.C., Reiss, A.L., 2005. White matter development during childhood and adolescence: a cross-sectional diffusion tensor imaging study. Cereb. Cortex 15, 1848-1854.

Bender, S., Weisbrod, M., Bornfleth, H., Resch, F., Oelkers-Ax, R., 2005. How do children prepare to react? Imaging maturation of motor preparation and stimulus anticipation by late contingent negative variation. Neuroimage 27, 737-752.

Brass, M., von Cramon, D.Y., 2002. The role of the frontal cortex in task preparation. Cereb. Cortex 12, 908-914.

Brown, T.T., Lugar, H.M., Coalson, R.S., Miezin, F.M., Petersen, S.E., Schlaggar, B.L., 2005. Developmental changes in human cerebral functional organization for word generation. Cereb. Cortex 15, 275-290.

Brown, M.R., Vilis, T., Everling, S., 2007. Frontoparietal activation with preparation for antisaccades. J. Neurophysiol. 98, 1751-1762.

Brown, M.R., Vilis, T., Everling, S., 2008. Isolation of saccade inhibition processes: rapid event-related fMRI of saccades and nogo trials. Neuroimage 39, 793-804.

Bruce, C.J., Goldberg, M.E., 1985. Primate frontal eye fields. I. Single neurons discharging before saccades. J. Neurophysiol. 53, 603-635.

Bunge, S.A., 2004. How we use rules to select actions: a review of evidence from cognitive neuroscience. Cogn. Affect. Behav. Neurosci. 4, 564-579.

Bunge, S.A., Dudukovic, N.M., Thomason, M.E., Vaidya, C.J., Gabrieli, J.D., 2002. Immature frontal lobe contributions to cognitive control in children: evidence from fMRI. Neuron $33,301-311$

Bunge, S.A., Wallis, J.D., Parker, A., Brass, M., Crone, E.A., Hoshi, E., Sakai, K., 2005. Neural circuitry underlying rule use in humans and nonhuman primates. J. Neurosci. 25, 10347-10350 (Review)

Burgund, E.D., Kang, H.C., Kelly, J.E., Buckner, R.L., Snyder, A.Z., Petersen, S.E., Schlaggar, B.L., 2002. The feasibility of a common stereotactic space for children and adults in fMRI studies of development. Neuroimage 17, 184-200.

Burock, M.A., Buckner, R.L., Woldorff, M.G., Rosen, B.R., Dale, A.M., 1998. Randomized event-related experimental designs allow for extremely rapid presentation rates using functional MRI. Neuroreport 9, 3735-3739.

Cameron, I.G., Pari, G., Alahyane, N., Brien, D.C., Coe, B.C., Stroman, P.W., Munoz, D.P. 2012. Impaired executive function signals in motor brain regions in Parkinson's disease. Neuroimage 60, 1156-1170.

Casey, B.J., Trainor, R.J., Orendi, J.L., Schubert, A.B., Nystrom, L.E., Giedd, J.N., Castellanos, F.X Haxby, J.V., Noll, D.C., Cohen, J.D., Forman, S.D., Dahl, R.E., Rapoport, J.L., 1997. A developmental functional MRI study of prefrontal activation during performance of a Go-No-Go task. J. Cogn. Neurosci. 9, 835-847.

Cherkasova, M.V., Manoach, D.S., Intriligator, J.M., Barton, J.J., 2002. Antisaccades and taskswitching: interactions in controlled processing. Exp. Brain Res. 144, 528-537.

Chikazoe, J., Jimura, K., Hirose, S., Yamashita, K., Miyashita, Y., Konishi, S., 2009. Preparation to inhibit a response complements response inhibition during performance of a stop-signal task. J. Neurosci. 29, 15870-15877.

Church, J.A., Petersen, S.E., Schlaggar, B.L., 2010. The "Task B problem" and other considerations in developmental functional neuroimaging. Hum. Brain Mapp. 31, 852-862 (Review).

Connolly, J.D., Goodale, M.A., Menon, R.S., Munoz, D.P., 2002. Human fMRI evidence for the neural correlates of preparatory set. Nat. Neurosci. 5, 1345-1352.

Connolly, J.D., Goodale, M.A., Goltz, H.C., Munoz, D.P., 2005. fMRI activation in the human frontal eye field is correlated with saccadic reaction time. J. Neurophysiol. 94, 605-611.

Crone, E.A., Donohue, S.E., Honomichl, R., Wendelken, C., Bunge, S.A., 2006. Brain regions mediating flexible rule use during development. J. Neurosci. 26, 11239-11247.

Curtis, C.E., Connolly, J.D., 2008. Saccade preparation signals in the human frontal and parietal cortices. J. Neurophysiol. 99, 133-145.

Curtis, C.E., D'Esposito, M., 2003. Success and failure suppressing reflexive behavior. J. Cogn. Neurosci. 15, 409-418.

Curtis, C.E., Cole, M.W., Rao, V.Y., D'Esposito, M., 2005. Canceling planned action: an FMRI study of countermanding saccades. Cereb. Cortex 15, 1281-1289.

Dale, A.M., 1999. Optimal experimental design for event-related fMRI. Hum. Brain Mapp. $8,109-114$

DeSouza, J.F., Menon, R.S., Everling, S., 2003. Preparatory set associated with pro-saccades and anti-saccades in humans investigated with event-related fMRI. J. Neurophysiol. 89, 1016-1023.

Dorris, M.C., Munoz, D.P., 1995. A neural correlate for the gap effect on saccadic reaction times in monkey. J. Neurophysiol. 73, 2558-2562.

Durston, S., Casey, B.J., 2006. What have we learned about cognitive development from neuroimaging? Neuropsychologia 44, 2149-2157.

Durston, S., Thomas, K.M., Yang, Y., Ulug, A.M., Zimmerman, R.D., Casey, B.J., 2002. A neural basis for the development of inhibitory control. Dev. Sci. 5 (4), F9-F16.

Durston, S., Davidson, M.C., Tottenham, N., Galvan, A., Spicer, J., Fossella, J.A., Casey, B.J., 2006. A shift from diffuse to focal cortical activity with development. Dev. Sci. 9, 1-8.

Dyckman, K.A., Camchong, J., Clementz, B.A., McDowell, J.E., 2007. An effect of context on saccade-related behavior and brain activity. Neuroimage 36, 774-784.

Ethridge, L.E., Brahmbhatt, S., Gao, Y., McDowell, J.E., Clementz, B.A., 2009. Consider the context: blocked versus interleaved presentation of antisaccade trials. Psychophysiology 46, 1100-1107. 
Ettinger, U., Ffytche, D.H., Kumari, V., Kathmann, N., Reuter, B., Zelaya, F., Williams, S.C., 2008. Decomposing the neural correlates of antisaccade eye movements using event-related FMRI. Cereb. Cortex 18, 1148-1159.

Everling, S., Munoz, D.P., 2000. Neuronal correlates for preparatory set associated with pro-saccades and anti-saccades in the primate frontal eye field. J. Neurosci. 20, 387-400.

Everling, S., Dorris, M.C., Munoz, D.P., 1998. Reflex suppression in the anti-saccade task is dependent on prestimulus neural processes. J. Neurophysiol. 80, 1584-1589.

Fischer, B., Biscaldi, M., Gezeck, S., 1997. On the development of voluntary and reflexive components in human saccade generation. Brain Res. 754, 285-297.

Flores, A.B., Digiacomo, M.R., Meneres, S., Trigo, E., Gómez, C.M., 2009. Development of preparatory activity indexed by the contingent negative variation in children. Brain Cogn. 71, 129-140.

Ford, K.A., Goltz, H.C., Brown, M.R., Everling, S., 2005. Neural processes associated with antisaccade task performance investigated with event-related fMRI. J. Neurophysiol. $94,429-440$.

Ford, K.A., Gati, J.S., Menon, R.S., Everling, S., 2009. BOLD fMRI activation for anti-saccades in nonhuman primates. Neuroimage $45,470-476$.

Geier, C.F., Terwilliger, R., Teslovich, T., Velanova, K., Luna, B., 2010. Immaturities in reward processing and its influence on inhibitory control in adolescence. Cereb. Cortex 20, 1613-1629.

Gogtay, N., Giedd, K.N., Lusk, L., Hayashi, K.M., Greenstein, D., Vaituzis, A.C., Nugent, T.F. Herman, D.H., Clasen, L.S., Toga, A.W., Rapoport, J.L., Thompson, P.M., 2004. Dynamic mapping of human cortical development during childhood through early adulthood. Proc. Natl. Acad. Sci. U. S. A. 101, 8174-8179.

Hakvoort Schwerdtfeger, R.M., Alahyane, N., Brien, D.C., Coe, B.C., Stroman, P.W., Munoz, D.P., 2013. Preparatory neural networks are impaired in adults with attention-deficit/ hyperactivity disorder during the antisaccade task. Neuroimage: Clin. 2, 63-78.

Hallett, P.E., 1978. Primary and secondary saccades to goals defined by instructions. Vis. Res. 18, 1279-1296.

Huttenlocher, P.R., 1990. Morphometric study of human cerebral cortex development Neuropsychologia 28, 517-527.

Huttenlocher, P.R., Dabholkar, A.S., 1997. Regional differences in synaptogenesis in human cerebral cortex. J. Comp. Neurol. 387, 167-178.

Hutton, S.B., Ettinger, U., 2006. The antisaccade task as a research tool in psychopathology: a critical review. Psychophysiology 43, 302-313 (Review).

Hwang, K., Velanova, K., Luna, B., 2010. Strengthening of top-down frontal cognitive control networks underlying the development of inhibitory control: a functional magnetic resonance imaging effective connectivity study. J. Neurosci. 30, 15535-15545.

Johnson, M.H., 2001. Functional brain development in humans. Nat. Rev. Neurosci. 2, 475-483.

Johnston, K., Everling, S., 2006. Monkey dorsolateral prefrontal cortex sends task-selective signals directly to the superior colliculus. J. Neurosci. 26, 12471-12478.

Johnston, K., Levin, H.M., Koval, M.J., Everling, S., 2007. Top-down control-signal dynamics in anterior cingulate and prefrontal cortex neurons following task switching. Neuron $53,453-462$

Jolles, D.D., Kleibeuker, S.W., Rombouts, S.A., Crone, E.A., 2011. Developmental differences in prefrontal activation during working memory maintenance and manipulation for different memory loads. Dev. Sci. 14, 713-724.

Jonkman, L.M., 2006. The development of preparation, conflict monitoring and inhibition from early childhood to young adulthood: a Go/Nogo ERP study. Brain Res. 1097, 181-193.

Kang, H.C., Burgund, E.D., Lugar, H.M., Petersen, S.E., Schlaggar, B.L., 2003. Comparison of functional activation foci in children and adults using a common stereotactic space. Neuroimage 19, 16-28.

Klein, C., Feige, B., 2005. An independent components analysis (ICA) approach to the study of developmental differences in the saccadic contingent negative variation. Biol. Psychol. 70, 105-114.

Klein, C., Foerster, F., 2001. Development of prosaccade and antisaccade task performance in participants aged 6 to 26 years. Psychophysiology 38, 179-189.

Koolschijn, P.C., Schel, M.A., de Rooij, M., Rombouts, S.A., Crone, E.A., 2011. A three-year longitudinal functional magnetic resonance imaging study of performance monitoring and test-retest reliability from childhood to early adulthood. J. Neurosci. 31, 4204-4212.

Koval, M.J., Lomber, S.G., Everling, S., 2011. Prefrontal cortex deactivation in macaques alters activity in the superior colliculus and impairs voluntary control of saccades. J. Neurosci. 31, 8659-8668

Kramer, A.F., de Sather, J.C., Cassavaugh, N.D., 2005. Development of attentional and oculomotor control. Dev. Psychol. 41, 760-772.

Kriegeskorte, N., Simmons, W.K., Bellgowan, P.S., Baker, C.I., 2009. Circular analysis in systems neuroscience: the dangers of double dipping. Nat. Neurosci. 12, 535-540 (Review).

Lenroot, R.K., Gogtay, N., Greenstein, D.K., Wells, E.M., Wallace, G.L., Clasen, L.S., Blumenthal, J.D., Lerch, J., Zijdenbos, A.P., Evans, A.C., Thompson, P.M., Giedd, J.N., 2007. Sexual dimorphism of brain developmental trajectories during childhood and adolescence. Neuroimage 36, 1065-1073.

Logothetis, N.K., Pauls, J., Augath, M., Trinath, T., Oeltermann, A., 2001. Neurophysiological investigation of the basis of the fMRI signal. Nature 412, 150-157.

Luna, B., Sweeney, J.A., 2004. The emergence of collaborative brain function: fMRI studies of the development of response inhibition. Ann. N. Y. Acad. Sci. 1021, 296-309.

Luna, B., Thulborn, K.R., Strojwas, M.H., McCurtain, B.J., Berman, R.A., Genovese, C.R. Sweeney, J.A., 1998. Dorsal cortical regions subserving visually guided saccades in humans: an fMRI study. Cereb. Cortex 8, 40-47.

Luna, B., Thulborn, K.R., Munoz, D.P., Merriam, E.P., Garver, K.E., Minchew, N.J., Keshavan, M.S., Genovese, C.R., Eddy, W.F., Sweeney, J.A., 2001. Maturation of widely distributed brain function subserves cognitive development. Neuroimage 13, 786-793.
Luna, B., Garver, K.E., Urban, T.A., Lazar, N.A., Sweeney, J.A., 2004. Maturation of cognitive processes from late childhood to adulthood. Child Dev. 75, 1357-1372.

Luna, B., Velanova, K., Geier, C.F., 2008. Development of eye-movement control. Brain Cogn. 68, 293-308 (Review).

Luna, B., Padmanabhan, A., O'Hearn, K., 2010. What has fMRI told us about the development of cognitive control through adolescence? Brain Cogn. 72, 101-113 (Review).

Manoach, D.S., Thakkar, K.N., Cain, M.S., Polli, F.E., Edelman, J.A., Fischl, B., Barton, J.J., 2007. Neural activity is modulated by trial history: a functional magnetic resonance imaging study of the effects of a previous antisaccade. J. Neurosci. 27, 1791-1798.

McDowell, J.E., Dyckman, K.A., Austin, B.P., Clementz, B.A., 2008. Neurophysiology and neuroanatomy of reflexive and volitional saccades: evidence from studies of humans. Brain Cogn. 68, 255-270 (Review).

Meiran, N., Daichman, A., 2005. Advance task preparation reduces task error rate in the cuing task-switching paradigm. Mem. Cognit. 33, 1272-1288.

Miezin, F.M., Macotta, L., Ollinger, J.M., Petersen, S.E., Buckner, R.L., 2000. Characterizing the hemodynamic response: effects of presentation rate, sampling procedure, and the possibility of ordering brain activity based on relative timing. Neuroimage 11 , 735-759.

Monsell, S., 2003. Task switching. Trends Cogn. Sci. 7, 134-140.

Munoz, D.P., Corneil, B.D., 1995. Evidence for interactions between target selection and visual fixation for saccade generation in humans. Exp. Brain Res. 103, 168-173.

Munoz, D.P., Everling, S., 2004. Look away: using the anti-saccade task to study voluntary control of movement. Nat. Rev. Neurosci. 5, 218-228.

Munoz, D.P., Broughton, J.R., Goldring, J.E., Armstrong, I.T., 1998. Age-related performance of human subjects on saccadic eye movement tasks. Exp. Brain Res. 121, $391-400$.

Murphy, K., Garavan, H., 2004. An empirical investigation into the number of subjects required for an event-related fMRI study. Neuroimage 22, 879-885.

Norman, A.L., Crocker, N., Mattson, S.N., Riley, E.P., 2009. Neuroimaging and fetal alcoho spectrum disorders. Dev. Disabil. Res. Rev. 15, 209-217 (Review).

Okazaki, S., Hosokawa, M., Kawakubo, Y., Ozaki, H., Maekawa, H., Futakami, S., 2004. Developmental change of neurocognitive motor behavior in a continuous performance test with different interstimulus intervals. Clin. Neurophysiol. 115, 1104-1113.

Olesen, P.J., Nagy, Z., Westerberg, H., Klingberg, T., 2003. Combined analysis of DTI and fMRI data reveals a joint maturation of white and grey matter in a fronto-parietal network. Brain Res. Cogn. Brain Res. 18, 48-57.

Olivier, I., Rival, C., 2002. Foreperiod duration and motor preparation during childhood. Neurosci. Lett. 319, 125-128.

Ollinger, J.M., Shulman, G.L., Corbetta, M., 2001a. Separating processes within a trial in event-related functional MRI. Neuroimage 13, 210-217.

Ollinger, J.M., Corbetta, M., Shulman, G.L., 2001b. Separating processes within a trial in event-related functional MRI. Neuroimage 13, 218-229.

Ordaz, S., Davis, S., Luna, B., 2010. Effects of response preparation on developmental improvements in inhibitory control. Acta Psychol. (Amst) 134, 253-263.

Orr, J.M., Weissman, D.H., 2009. Anterior cingulate cortex makes 2 contributions to minimizing distraction. Cereb. Cortex 19, 703-711.

Padmanabhan, A., Geier, C.F., Ordaz, S.J., Teslovich, T., Luna, B., 2011. Developmenta changes in brain function underlying the influence of reward processing on inhibitory control. Dev. Cogn. Neurosci. 1, 517-529.

Paus, T., 1996. Location and function of the human frontal eye-field: a selective review. Neuropsychologia 34, 475-483 (Review).

Paus, T., Petrides, M., Evans, A.C., Meyer, E., 1993. Role of the human anterior cingulate cortex in the control of oculomotor, manual, and speech responses: a positron emission tomography study. J. Neurophysiol. 70, 453-469.

Pierrot-Deseilligny, C., Milea, D., Müri, R.M., 2004. Eye movement control by the cerebral cortex. Curr. Opin. Neurol. 17, 17-25 (Review).

Poldrack, R.A., Mumford, J.A., 2009. Independence in ROI analysis: where is the voodoo? Soc. Cogn. Affect. Neurosci. 4, 208-213.

Rubia, K., Smith, A.B., Woolley, J., Nosarti, C., Heyman, I., Taylor, E., Brammer, M., 2006 Progressive increase of frontostriatal brain activation from childhood to adulthood during event-related tasks of cognitive control. Hum. Brain Mapp. 27, 973-993.

Sakai, K., 2008. Task set and prefrontal cortex. Annu. Rev. Neurosci. 31, 219-245 (Review).

Schiller, P.H., True, S.D., Conway, J.L., 1980. Deficits in eye movements following fronta eye field and superior colliculus ablations. J. Neurophysiol. 44, 1175-1189.

Snook, L., Paulson, L.A., Roy, D., Phillips, L., Beaulieu, C., 2005. Diffusion tensor imaging of neurodevelopment in children and young adults. Neuroimage 26, 1164-1173.

Sowell, E.R., Thompson, P.M., Holmes, C.J., Jernigan, T.L., Toga, A.W., 1999. In vivo evidence for post-adolescent brain maturation in frontal and striatal regions. Nature 2 859-861.

Sowell, E.R., Trauner, D.A., Gamst, A., Jernigan, T.L., 2002. Development of cortical and subcortical brain structures in childhood and adolescence: a structural MRI study Dev. Med. Child Neurol. 44, 4-16.

Sweeney, J.A., Takarae, Y., Macmillan, C., Luna, B., Minshew, N.J., 2004. Eye movements in neurodevelopmental disorders. Curr. Opin. Neurol. 17, 37-42 (Review).

Tamm, L., Menon, V., Reiss, A.L., 2002. Maturation of brain function associated with response inhibition. J. Am. Acad. Child Adolesc. Psychiatry 41, 1231-1238.

Toga, A.W., Thompson, P.M., Sowell, E.R., 2006. Mapping brain maturation. Trends Neurosci. 29, 148-159 (Review).

Velanova, K., Wheeler, M.E., Luna, B., 2008. Maturational changes in anterior cingulate and frontoparietal recruitment support the development of error processing and inhibitory control. Cereb. Cortex 18, 2505-2522.

Velanova, K., Wheeler, M.E., Luna, B., 2009. The maturation of task set-related activation supports late developmental improvements in inhibitory control. J. Neurosci. 29, 12558-12567. 
Viswanathan, A., Freeman, R.D., 2007. Neurometabolic coupling in cerebral cortex reflects synaptic more than spiking activity. Nat. Neurosci. 10, 1308-1312.

Watanabe, M., Munoz, D.P., 2010. Presetting basal ganglia for volitional actions. J. Neurosci. 30, 10144-10157.

Watanabe, M., Munoz, D.P., 2011. Probing basal ganglia functions by saccade eye movements. Eur. J. Neurosci. 33, 2070-2090.

Wenger, K.K., Visscher, K.M., Miezin, F.M., Petersen, S.E., Schlaggar, B.L., 2004. Comparison of sustained and transient activity in children and adults using a mixed blocked/ event-related fMRI design. Neuroimage 22, 975-985.
Wendelken, C., Munakata, Y., Baym, C., Souza, M., Bunge, S.A., 2012. Flexible rule use: common neural substrates in children and adults. Dev. Cogn. Neurosci. 2, 329-339. Yakovlev, P.I., Lecours, A.R., 1967. The myelogenetic cycles of regional maturation of the brain. In: Minkowski, A. (Ed.), Regional Development of the Brain in Early Life. Blackwell Scientific, Oxford, pp. 3-70. 